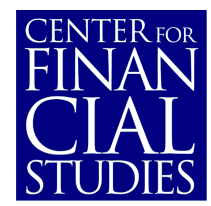

No. $2003 / 01$

\title{
Learning to Forecast and Cyclical Behavior of Output and Inflation
}

Klaus Adam

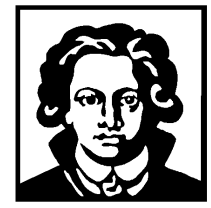

Center for Financial Studies 


\title{
Learning to Forecast and Cyclical Behavior of Output and Inflation
}

\author{
Klaus Adam ${ }^{1}$
}

November 2002

\begin{abstract}
:
This paper considers a sticky price model with a cash-in-advance constraint where agents forecast inflation rates with the help of econometric models. Agents use least squares learning to estimate two competing models of which one is consistent with rational expectations once learning is complete. When past performance governs the choice of forecast model, agents may prefer to use the inconsistent forecast model, which generates an equilibrium where forecasts are inefficient. While average output and inflation result the same as under rational expectations, higher moments differ substantially: output and inflation show persistence, inflation responds sluggishly to nominal disturbances, and the dynamic correlations of output and inflation match U.S. data surprisingly well.
\end{abstract}

JEL Classification: E31, E32, E37

Keywords: Learning, Business Cycles, Rational Expectations, Inefficient Forecasts, Output and Inflation Persistence

Klaus Adam, University of Frankfurt, Mertonstr.17, PF 94, 60054 Frankfurt, Germany, and Research Fellow at the Center for Financial Studies, E-mail: kladam@wiwi.uni-frankfurt.de

\footnotetext{
${ }^{1}$ I am grateful to Giuseppe Bertola, Matthias Brückner, Benjamin Friedman, Tullio Jappelli, Jordi Gali, Soeren Johansen, Albert Marcet, Ramon Marimon, Athanasios Orphanides, Philippe Weil and seminar participants at Bocconi, Harvard, ECB, European University Institute, FED, MIT, Pompeu Fabra, and ULB. All errors are mine.
} 


\section{Introduction}

One on the main objectives of macroeconomic modeling is to understand the joint behavior of aggregate output and inflation at the business cycle frequency. However, models with optimizing agents and nominal rigidities, workhorses of current macroeconomics, have substantial difficulties in capturing some of the key properties of U.S. output and inflation data. In particular, the persistence in inflation rates and the reaction of output and inflation to nominal disturbances turn out to be rather difficult to match, see Chari et al. (2000) and Nelson (1998). ${ }^{1}$

Since standard models impose rational expectations, deviations of expectations from perfect rationality are always among the usual suspects of the problem. Roberts (1997), for example, reinterpreting the model of Fuhrer and Moore (1995) as a sticky price model shows that boundedly rational inflation forecasts generate empirically plausible inflation behavior. Similar results have been reported by Ball (2000) who showed that introducing first-order autoregressive inflation expectations significantly improves the empirical performance of otherwise standard sticky price models. ${ }^{2}$

At the same time surveys on inflation expectations suggest that rational expectations in the strict sense are unlikely to hold; see Croushore $(1996,1998)$ for an overview and Friedman (1980) for an early study. Although forecasts have been found to be largely unbiased there is clear evidence that even professional forecasters do not make efficient use of all available data as rational expectations would imply.

Despite being empirically successful, models of output and inflation using imperfectly rational expectations do not provide micro-foundations for why agents might hold such

\footnotetext{
${ }^{1}$ More limited approaches that do not model output and inflation jointly such as Galí and Gertler (1999) and Galí, Gertler, and Lopez (2001) find that, conditional on output dynamics, sticky price models can explain inflation dynamics.

${ }^{2}$ Gali and Gertler (1999) report that non-rationalities would be quantitatively negligible. Again this holds only conditional on the observed output dynamics.
} 
expectations. ${ }^{3}$ Thus, when asking policy questions such models may deliver misleading predictions since they are subject to the Lucas critique. This severely limits their usefulness.

This paper presents a micro-foundation for why agents might hold inefficient expectations that is based on agents who adaptively learn to forecast future inflation rates. The paper shows that such agents may learn to make inefficient forecasts in the long-run and illustrates that the resulting equilibria can account for key features of U.S. output and inflation dynamics. Given the micro-foundations for the expectations formation process the model is not subject to the Lucas critique and can also be used to address policy questions. ${ }^{4}$

The paper uses a simple model of monopolistic competition with prices preset for one period where agents hold money due to a cash-in-advance constraint. The only deviation from a rational expectations approach consists of imposing that agents can choose between either of two forecasting models to predict future inflation rates and that they must learn the parameters of the forecast functions.

Although the restriction to two forecast models is crucial for the particular results that follow (detailed justifications for it are developed in the paper), the general mechanism underlying the results is fairly general and not specific to the particular setup of this paper. Moreover, the restriction on the forecast models is such that one of the forecast models can correspond to a rational expectations equilibrium once learning is complete. Thus, the restriction itself does not preclude that agents acquire rational expectations. Importantly, however, the second available forecast model is inconsistent with rational expectations and delivers misspecified forecasts for any parameterization. Nevertheless, I find that there are situations where agents prefer to use such a forecasting model.

The economic intuition underlying this finding is simple but general and the model in this paper provides just a minimal example where it is at work. Figure 1 illustrates the

\footnotetext{
${ }^{3}$ The theoretical literature dealing with less-than-rational expectations will be discussed below.

${ }^{4}$ Due to space constraints this is not dealt with in this paper.
} 


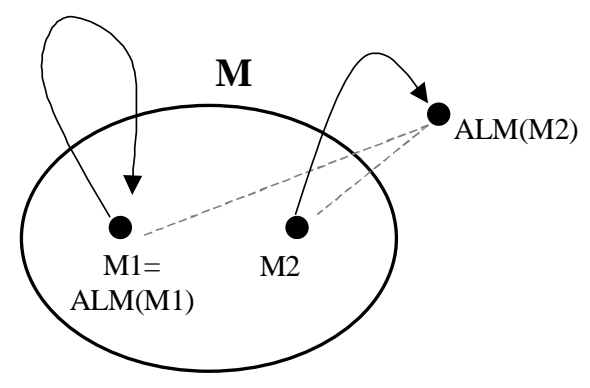

Figure 1: Emergence of Alternative Equilibria in the Presence of Forecasting Constraints intuition in a slightly simplified way. ${ }^{5}$ The set $M$ denotes a restriction on the class of forecast models, which implies that agents can employ only two forecast models, namely $M 1$ and $M 2$. While the use of $M 1$ induces an actual law of motion ( $A L M)$ for the forecasted variable that rationalizes the use of $M 1$, i.e. it generates a rational expectations equilibrium, use of $M 2$ generates an actual law of motion for the variable of interest that lies outside the class of forecasting schemes considered by agents. As a result, all considered forecasting schemes will be misspecified. Model $M 2$ may then give a better approximation to the $A L M$ it generates than $M 1$, as illustrated in figure 1 .

Thus, in the presence of forecasting restrictions inefficient equilibrium expectations can emerge whenever the class of considered forecast model is lacking a closedness property such that use of some forecast model complicates the actual law of motion in a way that none of the considered forecast models encompasses it anymore. ${ }^{6}$ In the resulting equilibria agents' forecasting schemes are still rational, given the forecasting constraints, but expectations are inefficient because they do not make use of all available information.

\footnotetext{
${ }^{5}$ The figure abstracts from the problem of the parameterization of forecast models.

${ }^{6}$ Equilibria with inefficient expectations exist although all agents consider the same class of forecast models. Such equilibria might be even more likely when different agents consider different classes, a line of research that still has to be explored.
} 
Given the multiplicity of equilibria, the paper adapts a learning approach to see whether these equilibria are stable with adaptively learning forecasters. Agents are assumed to use least squares learning to fit the forecast models to the data and to choose among the models according to past performance in terms of their mean squared forecast errors. Model selection based on mean squared errors is attractive from an economic viewpoint because it represents a quadratic approximation to the correct utility based choice citerion.

It is shown that efficient and inefficient expectations equilibria are equally learnable by such agents. ${ }^{7}$ Thus, inefficient expectations equilibria also constitute a plausible outcome of a reasonably general learning process.

While the idea of allowing choice in a limited class of forecast models has been developed before, this has not been done in a business cycle context. Most closely related is Evans and Honkapohja (1993) who consider an overlapping generations model where agents can choose between forecasting rules with different (constant) gain parameters, which can generate endogenous cycles. However, constant gain predictors are misspecified predictors for their model as they will never deliver rational expectations when agents use them to forecast. ${ }^{8}$ Also, Brock and Hommes (1997) consider a cobweb model where agents choose between rational and naive predictors and show that cyclical or even chaotic behavior may emerge. Yet, when all predictors are equally costly or when the infinite past is relevant for the predictor choice, as in this paper, then the rational expectations equilibrium remains the unique outcome. Evans and Ramey (1992) consider a model where agents can engage in costly expectation revisions and show that this may give rise to long run non-neutrality and hysteresis effects where agents hold non-rational expectations. Again, in the absence of calculation costs rational expectations remain the unique outcome.

Also the learning approach has rarely been taken to macroeconomic data as the existing literature remains largely theoretical. Exceptions are the early hyperinflation study by Cagan

\footnotetext{
${ }^{7}$ Some of the rational expectations equilibria turn out not to be learnable, though.

${ }^{8}$ In models where agents receive noisy signals about a random walk, constant gain predictors reproduce a Kalman filter estimate and thereby can deliver rational expectations.
} 
(1956), the paper by Marcet and Nicolini (1996), who analyze hyperinflations in South America in a model closely related to the one in this paper, and Sargent (1999) who explains the history of American inflation with policy makers who learn about the Phillips curve tradeoff. Recent applications of learning models to financial markets include Timmermann (1993), Kasa (2002), and Bossaerts (2002). Further applications of learning models to financial markets and macroeconomics can be found in the collection introduced by Arifovic and Bullard (2001).

In the equilibrium where expectations are inefficient white noise demand shocks are able to generate ample persistence and sluggishness in the time series. In particular, output and inflation show persistent deviations from steady state, inflation responds sluggishly to output deviations, inflation is an indicator of future output losses, and real wages tend to lag over the output cycle.

These features are all shared by U.S. data but do not show up when agents have rational expectations. In the rational expectations equilibrium output and inflation are just white noise and real wages are fully pro-cyclical. Moreover, all these features arise as long-run phenomena and not only along an adjustment path during which learning is taking place, provided the forecasting constraints remain in place.

Output deviations are persistent and inflation reacts sluggishly because price setting firms initially underreact to demand shocks. When expectations are inefficient firms condition their inflation forecasts on the current inflation rate, which is predetermined due to a price stickiness of one period. Consequently, their inflation expectations do not immediately pick up in response to a demand shock and inflation is initially only driven by increased cost expectations. When costs are reacting weakly to demand shocks, inflation will increase only slightly and cause the demand shock to persist into the following period. Once inflation increases, inflation expectations pick up and start to drive inflation. Indeed, inflation and inflation expectations will overreact and thereby cause a cyclical downturn in future periods.

The paper is organized as follows. Section 2 presents important features of U.S. output 
and inflation that business cycle models should match. The model is introduced in section 3 and its rational expectations solutions are outlined in section 4 . Section 5 introduces learning agents with forecasting constraints. Conditions under which such agents might acquire efficient and inefficient expectations are determined in section 6 which also compares the implied equilibrium dynamics with features of U.S. data presented in section 2. Section 7 then offers a discussion of the degree of forecast rationality and of the generality of the mechanism illustrated in figure 1 above. Finally, section 8 gives a brief outlook on work that lies ahead. Technical details can be found in the appendix.

\section{U.S. Output and Inflation: The Facts}

This section presents key features of the behavior of U.S. output and inflation that business cycle models should capture.

The subsequent analysis is based on log quarterly U.S. GNP data (not seasonally adjusted, from Q1:1959 to Q3:1999) at constant and current prices with quarterly inflation defined as the implicit GNP-deflator and transformed into yearly rates. As in Stock and Watson (1999) business cycle components have been obtained by using a band-pass filter on log-output and inflation. ${ }^{9}$ The filtered series are shown in figure $2 .^{10}$

Figure 3 depicts the auto- and crosscorrelations for a length of 24 quarters. Detrended output and inflation are positively autocorrelated for short lag lengths, which shows that there is considerable persistence in these variables. ${ }^{11}$ Both autocorrelations turn negative after about 5 quarters with the minimum at around 10 quarters. Thus, above average output (inflation) tends to be followed by below average output (inflation) circa $1 \frac{1}{4}$ to 4 years down

\footnotetext{
${ }^{9}$ The filter takes out fluctuations with a frequency below 2 and above 32 quarters to get rid of seasonal and trend components. Filtering with 4-32 quarters delivers the same results.

${ }^{10}$ Using a HP-filter with a smoothing parameter of 1600 leads to very similar results.

${ }^{11}$ Persistence might even be somewhat understated since the series have been detrended allowing for a time-varying trend component.
} 
the road with the maximum effect after circa $2 \frac{1}{2}$ years. These findings are consistent with the ones reported by Stock and Watson (1999).

The lower-left graph in figure 3 reveals that inflation is positively correlated with lagged output for the first 10 quarters, with the maximum correlation at 5 quarters. This suggests that inflation responds sluggishly to output deviations. Correspondingly, the upper-right graph shows that output is negatively correlated with lagged inflation for quarters 2 to 12 , with the maximum effect at around 6 quarters: inflation is an indicator of future output losses. Taylor (1999) has called these features the 'reverse dynamic cross correlation' of output and inflation.

Qualitatively similar results as the ones depicted in figure 3 have been reported by Fuhrer and Moore (1995) who estimated autocorrelation functions for output and inflation using a VAR that included a short term interest rate. ${ }^{12}$

While an analysis of the dynamic correlations is informative about the co-movements present in the data, it remains uninformative about the causes underlying these movements. Impulse response functions provide answers about potential causal links but require indentifying assumptions.

Figure 4 depicts the impulse response to a nominal demand shock obtained from fitting a vector autoregression (VAR) with 2 lags to yearly data. ${ }^{13}$ Identification of the demand shock is based on the model used later in this paper which assumes that prices are preset. Preset prices imply that prices cannot react to demand shock within the same period and thereby identify the shock. The identification assumption seems justified on the grounds that the benchmark results in Christiano, Eichenbaum, and Evans (1999) indicate that the GDP

\footnotetext{
${ }^{12}$ Fuhrer and Moore used linearly detrended non-farm business output and leave the inflation rate undetrended. These features might drive their finding of somewhat more persistent output and inflation.

${ }^{13}$ Yearly data was obtained by calculating averages of the quarterly values of each calendar year. Impulse responses for yearly data facilitate the comparison with the theoretical model in the remaining part of the paper. Details of the estimation and the impulse responses for a VAR with 1 lag can be found in appendix 9.1 .
} 
deflator reacts only after about 6 quarters to a monetary policy shock while output reacts well within the first 4 quarters.

Figure 4 shows the impulse response for a positive demand shock of a magnitude of one standard deviation. Output remains about 0.3 standard deviations above average in the year after the shock, illustrating that there is considerable output persistence. Inflation increases by 0.4 standard deviations in both years after the shock which indicates considerable sluggishness in the price response.

In summary, the preceding analysis suggests that business cycle models should match the following features: demand shocks should generate a persistent increase in output and a sluggish and persistent increase in inflation. Moreover, inflation should display persistence and should be followed by a persistent decrease in future output.

The simple model discussed in the remaining part of this paper can replicate all of these facts using white noise nominal demand disturbances as driving forces.

\section{A Simple Business Cycle Model}

This section outlines a highly stylized business cycle model with utility maximizing consumers, profit maximizing entrepreneurs, and a government that finances expenditure shocks through seignorage.

There are two deviations from a frictionless environment, which insure that agents hold money in equilibrium and guarantee that monetary policy has real effects under rational expectations. Firstly, firms must commit to prices one period in advance, however can reset them each period. Secondly, consumption is subject to a cash-in-advance constraint forcing agents to use money to finance current consumption.

There is a unit mass of entrepreneurs who own monopolistically competitive firms. Each entrepreneur $i$ produces an intermediate consumption good $q^{i}$ that is an imperfect 
substitute in the construction of an aggregate consumption good $c$ :

$$
c=\left(\int_{i \in[\mathbf{0}, 1]}\left(q^{i}\right)^{1-\sigma}\right)^{\frac{1}{1-\sigma}} \quad \text { with } 1>\sigma \geq 0
$$

where $\sigma$ indexes the degree of imperfect competition (Dixit and Stiglitz (1977)). This setup gives rise constant elasticity demand functions and implies that each entrepreneur $i$ maximizes expected profits by choosing its price $P_{t}^{i}$ as a fixed mark-up over expected production costs:

$$
P_{t}^{i}=\frac{1}{1-\sigma} E_{t-1}\left[P_{t} w_{t}\right]
$$

The previous equation assumes that the production technology is linear in labor such that nominal marginal costs are given by the product of the price index of the final consumption good $P_{t}$ and the real wage $w_{t}$.

Dividing the previous equation by $P_{t-1}$ and assuming that entrepreneurs have identical expectations delivers

$$
\Pi_{t}=\frac{1}{1-\sigma} E_{t-1}\left[\Pi_{t} w_{t}\right]
$$

where $\Pi_{t}=\frac{P_{t}}{P_{t-1}}$ is the inflation factor from period $t-1$ to period $t .{ }^{14}$

With a unit mass of workers, each worker $j$ chooses consumption $c_{t}^{j}$ and labor supply $n_{t}^{j}$ to maximize:

$$
\begin{aligned}
\max _{\left\{c_{t}^{j}, n_{t}^{j}\right\}} E_{t} \sum_{t=0}^{\infty} \beta^{t}\left(u\left(c_{t}^{j}\right)-v\left(n_{t}^{j}\right)\right) & \text { s.t. } \\
& c_{t}^{j} \leq \frac{m_{t-1}^{j}}{\Pi_{t}} \\
& m_{t}^{j}=\frac{m_{t-1}^{j}}{\Pi_{t}}-c_{t}^{j}+n_{t}^{j} w_{t}
\end{aligned}
$$

where $m_{t}^{j}$ denotes the worker's real money holdings at the end of period $t$. The first constraint forces workers to use cash to pay for consumption goods (with leisure being the credit good)

\footnotetext{
${ }^{14}$ Note that $\Pi_{t}$ is part of the $t-1$ information set $\Omega_{t-1}$ in equilibrium. Yet, out of equilibrium this is not the case. Since the paper is concerned with disequilibrium learning dynamics, $\Pi_{t}$ is part of $\Omega_{t}$.
} 
while the second constraint is the workers' flow budget constraint..$^{15}$

When $u, v \in C^{2}, u^{\prime}>0, u^{\prime \prime}<0, v^{\prime}>0, v^{\prime \prime} \geq 0,-\frac{u^{\prime \prime}(c) \cdot c}{u^{\prime}(c)}<1$ for all $c \geq 0$, and the cash-in-advance constraint is binding, utility maximization implies a labor supply function of the form:

$$
n_{t}=n\left(w_{t}, E_{t}\left[\Pi_{t+1}\right]\right)
$$

Inverting this labor supply function with respect to the first argument and imposing market clearing delivers the equilibrium real wage in the economy: ${ }^{16}$

$$
w_{t}=w\left(y_{t}, E_{t}\left[\Pi_{t+1}\right]\right) \quad \text { with } \quad \frac{\partial w}{\partial y}>0, \frac{\partial w}{\partial E_{t}\left[\Pi_{t+1}\right]}>0
$$

Given the specified utility functions, the equilibrium real wage increases in the demand for labor and in the expected inflation tax. ${ }^{17}$

It is assumed that the government finances real expenditure shocks $v_{t}$ through seignorage. ${ }^{18}$ This causes real money balances to evolve according to

$$
m_{t}=\frac{m_{t-1}}{\Pi_{t}}+v_{t}
$$

The demand shocks $v_{t}$ are assumed to be white noise and are the only source of randomness in the model. When prices are preset and the cash-in-advance constraint is binding, output

\footnotetext{
${ }^{15}$ Profits do not show up in the workers' budget constraint because these are consumed by entrepreneurs. This simplifying assumption avoids dependence of workers' labor supply function on expected profits and simplifies the analysis of the learning setup.

${ }^{16}$ In equilibrium aggregate output $y_{t}$ is equal to aggregate labor supply $n_{t}$ given the production function.

${ }^{17}$ Given that there is no role for the intra-period risk aversion in the present paper, the condition on the relative risk aversion that guarantees the signs of the derivatives should be interpreted in terms of the elasticity of intertemporal substitution. This could be seen as a short-cut for an Epstein-Zin utility function.

${ }^{18}$ Government spending is either wasteful or generates utility that is seperable from that of private consumption and leisure such that private sector decisions remain unaffected. Strictly speaking, this implies that there is no distinction between monetary and fiscal policy. However, redistribution of the seignorage in the form of lump sum transfers would not make any difference for the results as long as the cash-in-advance constraint is sufficiently binding. Thus, shocks could also be interpreted as monetary policy shocks.
} 
is demand determined in the short run and the previous equation is a specification of the demand side of the economy. ${ }^{19}$ This implies that output can be written as

$$
y_{t}=\frac{y_{t-1}}{\Pi_{t}}+v_{t}
$$

Using (1), (2), and (3) one obtains the temporary equilibrium equations that describe current output and inflation as a function of past output and expectations about future inflation rates:

$$
\begin{aligned}
\Pi_{t} & =\frac{1}{1-\sigma} E_{t-1}\left[\Pi_{t} w\left(\frac{y_{t-1}}{\Pi_{t}}+v_{t}, \Pi_{t+1}\right)\right] \\
y_{t} & =\frac{(1-\sigma) y_{t-1}}{E_{t-1}\left[\Pi_{t} w\left(\frac{y_{t-1}}{\Pi_{t}}+v_{t}, \Pi_{t+1}\right)\right]}+v_{t}
\end{aligned}
$$

The remaining part of the paper will consider the linearizations of these equations around the deterministic steady state equilibrium and will make different assumptions about how agents forecast the inflation rates appearing in (4) and (5).

\section{Rational Expectations Equilibria}

The deterministic steady state of the model is given by: ${ }^{20}$

$$
\begin{aligned}
\Pi^{s s} & =1 \\
y^{s s} & =n(1-\sigma, 1)
\end{aligned}
$$

\footnotetext{
${ }^{19}$ Along a deterministic equilibrium path where the expected inflation factor is above the discount factor, the cash-in-advance constraint strictly binds if period zero money balances are not too high. Also in the stochastic case with small support for the shocks surprise deflation will not be too high, which implies that real balances will not turn out to be so high that agents wish to postpone consumption and save using money.

${ }^{20}$ There exists another deterministic steady state where money is not used. However, its stochastic version does not exist because the government cannot use money to finance the expenditure shocks.
} 
Inflation is zero in the absence of seignorage. ${ }^{21}$ Linearizing (4) and (5) around the deterministic steady state yields the following linear approximation for the stochastic system: ${ }^{22}$

$$
\begin{aligned}
\left(\begin{array}{l}
\Pi_{t} \\
y_{t}
\end{array}\right) & =\left(\begin{array}{c}
-1 \\
2 y^{s s}
\end{array}\right)+\left(\begin{array}{c}
1-\frac{1}{\varepsilon_{n, w}} \\
-y^{s s}\left(1-\frac{1}{\varepsilon_{n, w}}\right)
\end{array}\right) E_{t-1}\left[\Pi_{t}\right] \\
& +\left(\begin{array}{c}
1 \\
-y^{s s}
\end{array}\right) E_{t-1}\left[\Pi_{t+1}\right]+\left(\begin{array}{c}
\frac{1}{y^{s s} \varepsilon_{n, w}} \\
1-\frac{1}{\varepsilon_{n, w}}
\end{array}\right) y_{t-1}+\left(\begin{array}{c}
0 \\
v_{t}
\end{array}\right)
\end{aligned}
$$

where $\varepsilon_{n, w}$ denotes the real wage elasticity of labor supply at the deterministic steady state. A convenient feature of the model is that, given the steady state values, the real wage elasticity is the only free parameter of the model.

In appendix 9.2 it is shown that the rational expectations solutions to (6) have a minimum state variable representation as a two-dimensional $\mathrm{AR}(1)$ process

$$
\left(\begin{array}{c}
\Pi_{t} \\
y_{t}
\end{array}\right)=a+B\left(\begin{array}{c}
\Pi_{t-1} \\
y_{t-1}
\end{array}\right)+\left(\begin{array}{c}
0 \\
v_{t}
\end{array}\right)
$$

There are two rational expectations solutions of this form. There is a stationary one, which is given by

$$
\left(\begin{array}{c}
\Pi_{t} \\
y_{t}
\end{array}\right)=\left(\begin{array}{c}
0 \\
y^{s s}
\end{array}\right)+\left(\begin{array}{cc}
0 & \frac{1}{y^{s s}} \\
0 & 0
\end{array}\right)\left(\begin{array}{c}
\Pi_{t-1} \\
y_{t-1}
\end{array}\right)+\left(\begin{array}{c}
0 \\
v_{t}
\end{array}\right)
$$

Output in this equilibrium is white noise and inflation is lagging output deviations by one period. There exists also a non-stationary solution given by:

$$
\left(\begin{array}{l}
\Pi_{t} \\
y_{t}
\end{array}\right)=\left(\begin{array}{c}
1+\varepsilon_{n, w} \\
-y^{s s} \frac{1}{\varepsilon_{n, w}}
\end{array}\right)+\left(\begin{array}{cc}
0 & -\frac{1}{\varepsilon_{n, w}} \frac{1}{y^{s s}} \\
0 & 1+\frac{1}{\varepsilon_{n, w}}
\end{array}\right)\left(\begin{array}{c}
\Pi_{t-1} \\
y_{t-1}
\end{array}\right)+\left(\begin{array}{c}
0 \\
v_{t}
\end{array}\right)
$$

As one can easily see, this equilibrium path is diverging from the steady state. The diverging paths have either increasing inflation rates and decreasing output levels or decreasing inflation rates and increasing output levels. ${ }^{23}$

\footnotetext{
${ }^{21}$ One could easily accomodate a deterministic seignorage term and generate positive steady state inflation.

${ }^{22}$ The linearization uses the fact that $\frac{\partial w / \partial E \Pi_{t+1}}{w}=1$ in a steady state where $\Pi=1$, which follows from the first order conditions of workers.

${ }^{23}$ The path with increasing output levels exists only in a local sense, see Adam (2002a) for details.
} 


\section{$5 \quad$ Learning to Forecast Inflation Rates}

While the previous section considered rational inflation forecasts, this section assumes that forecasts must be generated by econometric models and that agents consider a limited class of models. The section describes how agents estimate and select between these models and presents the equilibrium concept used in the remaining part of the paper.

\subsection{The Class of Forecast Models}

This section presents the restriction on the class of models that agents can use for forecasting. Importantly, the restriction will be such that forecast models that are consistent with the rational expectations solutions of the economy will not be excluded from the considered class. Therefore, the restriction in itself does not prevent agents from behaving in an unconstrained optimal way. Yet, the class of models will also contain forecast models that are inconsistent with the rational expectations solution of the economy. These are forecast models that when applied to forecasting inflation will never generate a path for inflation that is consistent with the way inflation is forecasted. This seems to be a reasonable starting point if agents do not possess a priori knowledge about the structure of the economy's rational expectations solution.

In particular, agents' forecasting models are restricted to the class of simple regression models of the form

$$
\Pi_{t}=\alpha_{t-1}+\beta_{t-1} x_{t-1}+\varepsilon_{t}
$$

where $x$ is an explanatory variable that is believed to predict future inflation. The parameters $\left(\alpha_{t-1}, \beta_{t-1}\right)$ denote agents' (least squares) estimates of the relationship between $x_{t-1}$ and $\Pi_{t}$. These estimates are based on information up to time $t-1$ and are constantly reestimated, however, for simplicity we will drop the time subscripts subsequently. Since the economy is described by two state variables, i.e. real output and inflation, the class of models (10) 
contains just two forecast models

$$
\begin{aligned}
& \text { Model Y : } \Pi_{t}=\alpha_{Y}+\beta_{Y} y_{t-1} \\
& \text { Model } \Pi: \Pi_{t}=\alpha_{\Pi}+\beta_{\Pi} \Pi_{t-1}
\end{aligned}
$$

where Model Y conditions inflation forecasts on past output and Model $\Pi$ on past inflation. While Model Y can generate the expectations of the stationary and non-stationary rational expectations equilibria (8) and (9), Model $\Pi$ will never generate rational expectations.

What economic interpretation can be given to the presence of a restriction on the class of forecast models?

Firstly, one may interpret the restriction as an exogenous restriction imposed on agents via the available prediction technology. The size of the class of forecast models then captures agents' computational knowledge or, more specifically, their knowledge about forecast procedures. Evidence obtained from the experimental laboratory has given strong support to the notion that agents' forecasting technology is described by univariate forecasting models, see Adam (2002b). Thus, if the sophistication of students participating in the experiments resembles that of firms operating in the economy such forecasting restrictions must be considered as plausible. ${ }^{24}$ Moreover, given that the economic model is highly stylized and therefore simplified with respect to reality, skeptical readers may interpret the restriction as a parable for more sophisticated agents in a more complicated economic environment.

Secondly, the restriction may be interpreted as the result of an optimal choice of a class of models that trades-off the forecasting performance with the cost of considering smaller or larger classes of forecast models. The class is then an artefact of existing calculation costs. In section 7 it is shown that for an arbitrarily small increase in calculation costs for larger model classes, there exists a threshold for the variance of the government demand shocks below which consideration of larger classes does not pay.

\footnotetext{
${ }^{24}$ Obviously, such a restriction seems unplausible for markets dominated by sophisticated forecasting experts such as financial markets.
} 
Thirdly, a restricted class of forecast models can be seen as a temporary phenomenon due to agents who perform a specification search for suitable forecast models and start out by considering a certain class of models. Unsatisfactory prediction performance may then lead to changes in the considered class. Section 7 shows that on average 33 data points are needed to reject white noise errors for the case that rational expectations are not obtained when considering the above class. This would make up a considerable part of post-war data sets, even when interpreting model periods a quarters. ${ }^{25}$

In principle all three economic interpretations are consistent with the setup of the model. A further discussion of the forecast errors that may be caused by the restriction above and the consequences of relaxing it can be found in section 7 .

\subsection{Choosing and Estimating Forecast Models}

To choose between and to parameterize the forecast models it is assumed that agents use the mean squared error criterion, which constitutes a second order approximation to the correct utility based choice criterion. ${ }^{26}$ In particular, agents use ordinary least squares to estimate parameters $\alpha$ and $\beta$ of the forecast models and choose the model with the lowest past mean squared forecast error to predict future inflation. ${ }^{27}$

There is a long-lived and controversial debate in econometrics about how one should choose, construct, modify, and test econometric models in order to obtain the 'true' model. Using the mean squared forecast error as a selection criterion is certainly not a very popular method. Yet, squared forecast errors are equivalent to using the $R^{2}$-value as a selection criterion. Since the $R^{2}$-value is equal to the square of the correlation coefficient between the data and the fitted values, it is a measure of the model's predictive power over the sample

\footnotetext{
${ }^{25}$ Given the degree of price stickiness an interpretation as a year seems more reasonable.

${ }^{26}$ This holds because least squares produce uncondionally unbiased estimates such that the first order terms drop off.

${ }^{27}$ Agents do not assign probabilities to different models according to the likelihood with which they believe them to be the best forecast model, rather they rely entirely on the model with the best past performance.
} 
period. ${ }^{28}$ When predictive power in the past is an indicator for good prediction performance in the future models with higher $R^{2}$ should indeed be the preferred forecast models. Moreover, the $R^{2}$ measure is strictly increasing with the $F$-Statistic on the significance of all retained variable regressors. ${ }^{29}$ In this sense the model with the higher $R^{2}$-value contains the more significant regression variable $x$. Finally, more sophisticated selection criteria also face important shortcomings such as the sensitivity of the results to the order of the tests that are applied to the statistical models. ${ }^{30}$

\subsection{Equilibrium with Learning Agents}

Given the learning behavior, the economy will evolve as explained in the following. Each period agents estimate both Model $\mathrm{Y}$ and $\Pi$ by ordinary least squares and choose the model with the lowest past mean squared forecast error to forecast inflation. All agents then maximize utility under the assumption that the future evolution of the economy is given by the point forecast produced by the selected forecast model. ${ }^{31}$ This generates a new inflation rate and output level as given by equation (6), where the operator $E[\cdot]$ might now denote the potentially non-rational expectations of the chosen forecast model. Using the new data point, agents adapt their least squares estimates and their model choices, and the process repeats itself.

An equilibrium is a situation where the new inflation rate and output level confirm the previous estimates and the previous model choice. Formally

\footnotetext{
${ }^{28}$ Note that this holds only for single equation regressions that assume uncorrelated errors and include an intercept term, see chapter 6.2 in Judge et. al. (1980).

${ }^{29}$ The caveats of the previous footnote apply.

${ }^{30}$ See also chapter 11 in Judge et al. (1980) for a whole list of model selection criteria and their shortcomings.

${ }^{31}$ Such an approach is justified on the following grounds: Given the unbiasedness of forecast based on least-squares estimates, the point forecast can be interpreted as the expected realization of the forecasted variable. When considering local convergence in a linearized version of the economy, certainty-equivalence holds.
} 
Definition 1 A Model Equilibrium consists of least squares estimates $\left(\alpha_{Y}^{*}, \beta_{Y}^{*}\right)$ and $\left(\alpha_{\Pi}^{*}, \beta_{\Pi}^{*}\right)$ for Model $Y$ and $\Pi$, respectively, and all agents using either Model $Y$ or Model $\Pi$ to forecast inflation rates such that

i. Agents choose the model with minimum mean squared forecast error.

ii. Given the forecast behavior, the economic outcomes resulting from (6) reconfirm the least squares estimates $\left(\alpha_{Y}^{*}, \beta_{Y}^{*}\right)$ and $\left(\alpha_{\Pi}^{*}, \beta_{\Pi}^{*}\right)$.

An equilibrium where agents use Model $M(M=Y, \Pi)$ to forecast inflation will be called a Model $M$ Equilibrium. ${ }^{32}$ The definition implies that in equilibrium agents forecast optimally, given the constraint on the available forecast models that are imposed upon them. In this sense agents forecasts will be rational in any potential Model Equilibrium.

The equilibrium concept above is most closely related to the restricted perceptions equilibrium in Evans and Honkapohja (2001) and the rational expectations equilibria with econometric models of Anderson and Sonnenschein (1985). However, both equilibrium concepts are defined in terms of the regressors that enter the agents' (single) forecast function, while the present notion requires to specify the restrictions in terms of the class of forecast models.

Also related are the consistent-expectations equilibrium of Hommes and Sorger (1997) and the self-confirming equilibrium of Fudenberg and Levine (1993) recently used by Sargent (1999) in a macroeconomic context. Both types of equilibria are also equilibria in the sense of definition 1. However, the converse is not true because Model Equilibria allow for autocorrelation in the forecasts errors.

\footnotetext{
${ }^{32}$ Note that the definition excludes equilibria where some share of agents uses Model $Y$ to forecast and the remaining agents use Model $\Pi$. In the present model such equilibria are not robust to small perturbations in the share of agents using the respective models.
} 


\section{Calculating Model Equilibria}

This section derives conditions under which Model $Y$ and Model $\Pi$ Equilibria exist and compares their properties with U.S. data.

\subsection{Model Y Equilibria}

Suppose that agents use Model $\mathrm{Y}$ to forecast inflation rates. Substituting the forecasts of Model $\mathrm{Y}$ for the expectations in the temporary equilibrium equations (6) delivers that the actual law of motion for inflation will be given by

$$
\Pi_{t}=a\left(\alpha_{Y}, \beta_{Y}\right)+b\left(\alpha_{Y}, \beta_{Y}\right) y_{t-1}
$$

where the coefficients $a$ and $b$ depend on agents' least squares estimates $\alpha_{Y}$ and $\beta_{Y}$.

Equation (11) reveals that the actual law of motion for inflation coincides with the structural assumption of Model Y, which implies that in a Model Y Equilibrium

$$
a\left(\alpha_{Y}, b_{Y}\right)=\alpha_{Y} \quad \text { and } \quad b\left(\alpha_{Y}, \beta_{Y}\right)=\beta_{Y}
$$

Otherwise the parameter estimates would not remain stable. Consequently, a Model Y Equilibrium is a rational expectations equilibrium.

The converse is not necessarily true. At a Model Equilibrium the least squares estimates of the forecast models must get reconfirmed, which excludes rational expectations equilibria that are unstable under least squares learning. As shown in appendix 9.3, the stationary rational expectations equilibrium (8) is the unique Model Y Equilibrium since the nonstationary equilibrium (9) is unstable under least squares learning. ${ }^{33}$

\footnotetext{
${ }^{33}$ At the latter equilibrium agents adapt their least squares estimates in response to shocks in a way such that their adapted expectations generate new inflation rates and output levels that cause these estimates to diverge even further.
} 
Output and inflation in Model Y Equilibrium are thus given by

$$
\begin{aligned}
\Pi_{t} & =\frac{1}{y^{s s}} y_{t-1} \\
y_{t} & =y^{s s}+v_{t}
\end{aligned}
$$

A one percent demand shock increases temporarily output and money holdings by the same amount. With equation (12) being identical to agents' Model Y estimate, the increased money stock (correctly) causes inflation expectations to increase by one percent. This causes entrepreneurs to increase their prices by exactly one percent (see equation (1) and note that the expected wage is equal to $1-\sigma$ ) which implies that the excess money stock will be devaluated by the next period.

As a result, shocks show no persistence and the rational expectations dynamics are unable to match the stylized facts presented in section 2. Indeed, the rational expectations equilibrium performs well only along a single dimension: current excess output leads to inflation in the subsequent period, due to sticky prices.

\subsection{Model П Equilibria}

This section considers equilibria where agents use Model $\Pi$ to predict inflation rates.

\subsubsection{Preliminaries}

Suppose agents use Model $\Pi$ to forecast inflation rates. This implies that expectations will be inefficient because there exists no rational expectations equilibrium where inflation depends on past inflation. Yet, least squares estimates deliver forecasts that are (on average) unbiased. As a result, average inflation in a Model $\Pi$ Equilibrium will coincide with average expected inflation, which holds only at (rational expectations) steady states. Therefore, average output and average inflation in a stationary Model $\Pi$ Equilibrium will be equal to these values in a Model $Y$ Equilibrium. ${ }^{34}$

\footnotetext{
${ }^{34}$ This does not need to hold for non-stationary equilibria.
} 
This feature makes inefficient equilibrium expectations a powerful tool to improve the match of a model's second moments with the data without altering its first moments. Moreover, on a more technical level, it implies that one can linearize the model around the same values as one usually does when calculating the linearized rational expectations solutions.

Substituting the predictions of Model $\Pi$ for the inflation expectations in (6) delivers an equation that describes current inflation and output as a function of the past values of these variables, the Model $\Pi$ parameters $\left(\alpha_{\Pi}, \beta_{\Pi}\right)$, and the labor supply elasticity $\varepsilon_{n, w}:{ }^{35}$

$$
\begin{aligned}
\left(\begin{array}{c}
\Pi_{t} \\
y_{t}
\end{array}\right) & =\left(\begin{array}{c}
-1+\alpha_{\Pi}\left(2+\beta_{\Pi}-\frac{1}{\varepsilon_{n, w}}\right) \\
\left(2-\alpha_{\Pi}\left(2+\beta_{\Pi}-\frac{1}{\varepsilon_{n, w}}\right)\right) y^{s s}
\end{array}\right) \\
& +\left(\begin{array}{cc}
\left(1+\beta_{\Pi}-\frac{1}{\varepsilon_{n, w}}\right) \beta_{\Pi} & \frac{1}{\varepsilon_{n, w}} \frac{1}{y^{s s}} \\
-\left(1+\beta_{\Pi}-\frac{1}{\varepsilon_{n, w}}\right) \beta_{\Pi} y^{s s} & 1-\frac{1}{\varepsilon_{n, w}}
\end{array}\right)\left(\begin{array}{c}
\Pi_{t-1} \\
y_{t-1}
\end{array}\right)+\left(\begin{array}{c}
0 \\
v_{t}
\end{array}\right)
\end{aligned}
$$

The preceding equation reveals that in a potential Model $\Pi$ Equilibrium inflation depends (generically) on past inflation and past output. Therefore, the actual law of motion for inflation lies outside the class of forecast models that agents consider. As a result, all forecast models are necessarily misspecified in some way, which implies that Model $\Pi$ possibly gives a better fit to (14) than Model Y.

From the preceding discussion it should be clear that a precondition for the existence of equilibria with inefficient expectations is that the class of forecast models is open under the structural relations of the economy, as given by the temporary equilibrium equations (6).

In the present case, there is an obvious way to close the class of forecast models. When agents consider somewhat more complicated models of the form

$$
\Pi_{t}=\alpha+\beta y_{t-1}+\gamma \Pi_{t-1}
$$

\footnotetext{
${ }^{35}$ The relevant features of this process are unaffected by the average level of output $y^{s s}$.
} 
then the actual law of motion for inflation still depends on past output and past inflation only. A Model Equilibrium is then a rational expectations equilibrium.

In general, there is no simple way to obtain a closed class of forecast models unless one restricts consideration to linear economies and allows agents to employ all (or at least a sufficiently large class of) linear forecast models. Since linear forecasts in a linear economy will produce linear actual laws of motions, the class will be closed. However, already allowing for non-linear forecasts in a linear economy will easily lead to an open class of forecast models. Also there is no obvious way to get a closed class in non-linear models, let alone in models where agents are allowed to consider different classes of forecast models. Thus, the openness of the proposed class of forecast models should be considered to be a virtue and not a shortcoming, given that openness can be expected to be likely in more realistic models.

\subsubsection{Existence of Model П Equilibria}

This section discusses under which conditions Model ПI Equilibria exist.

In a potential Model $\Pi$ Equilibrium the least squares estimate $\beta_{\Pi}$ must be identical to the correlation coefficient

$$
\frac{\operatorname{cov}\left(\Pi_{t}, \Pi_{t-1}\right)}{\operatorname{var}\left(\Pi_{t}\right)}
$$

of the actual law of motion (14). Since $\beta_{\Pi}$ enters (14), calculating a Model $\Pi$ equilibrium involves solving a fixed point problem, as when calculating a standard rational expectations equilibrium.

Appendix 9.4 shows how to solve for the fixed point $\beta_{\Pi}^{*}$ and figure 5 graphs the solution as a function of the parameter $\varepsilon_{n, w}$.

When $\varepsilon_{n, w}=1$, a one percent demand shock causes a one percent increase in expected costs and, thus, in inflation. This amount of inflation devaluates excess money just back to its equilibrium level. As a result, there is no persistence in excess demands, inflation is white noise, and $\beta_{\Pi}^{*}$ is equal to zero. ${ }^{36}$

\footnotetext{
${ }^{36}$ Curiously, when $\varepsilon_{n, w}=1$ firms with Model $\Pi$ expectations set the same prices as firms with (uncon-
} 
As labor supply becomes more elastic, a one percent demand shock generates a less than one percent labor cost and inflation increase. The excess money balances are not devaluated in a single period but persist into future periods where they cause again above average costs and inflation. Inflation rates are then positively autocorrelated which explains the positive slope in figure 5 .

Substituting the solution depicted in figure (5) into (14) yields a candidate process for a Model $\Pi$ equilibrium. ${ }^{37}$ Importantly, the properties of this process depend only on the elasticity $\varepsilon_{n, w}$. Numerical calculations show that the process is stationary for $0.35 \leq \varepsilon_{n, w} \leq$ 2.15 which will be the range of values considered from now on. ${ }^{38}$

For this candidate process to be a Model $\Pi$ Equilibrium one has to verify that Model $\Pi$ is predicting inflation better than Model Y. Clearly, for values of $\varepsilon_{n, w}$ around 1 this cannot be expected, since past inflation has almost no predictive power. However, for larger and smaller values inflation becomes an increasingly better predictor since inflation rates are autocorrelated, as shown in figure 5 .

Figure (6) depicts the mean squared forecast errors of Model $Y$ and Model $\Pi$ for various values of $\varepsilon_{n, w}$ assuming that agents use Model $\Pi$ to forecast. The graph reveals that for $\varepsilon_{n, w} \geq 1.75$ Model $\Pi$ will generate better predictions than Model Y. Potential Model $\Pi$ Equilibria therefore exist for $1.75 \leq \varepsilon_{n, w} \leq 2.25$

Finally, in appendix 9.3 it is shown that the potential Model $\Pi$ Equilibria are stable under least squares learning, which establishes that Model $\Pi$ Equilibria exist for elasticity values between 1.75 and 2.15 .

Admittedly, the required supply elasticity lies on the high end of plausible values. However, similar elasticity levels are not uncommon in the literature. Christiano et al.(1997), for strained) rational expectations, although for the wrong reasons: it is not costs that will increase as expected (output will be back at the equilibrium value on average) but inflation.

${ }^{37}$ One also has to set $\alpha_{\Pi}^{*}=1-\beta_{\Pi}^{*}$, which follows from the unbiasedness of least squares forecasts.

${ }^{38}$ The boundaries are only approximate. 
example, report satisfactory performance of a limited participation model for a labor supply elasticity of 2. Moreover, labor is the unique variable input factor in the present model. Therefore, the elasticity should rather be interpreted as an elasticity of total marginal costs of production, which includes other variable factors such as capital (in terms of utilization rates), raw materials, and energy. Moreover, one should be concerned with working hours which include overtime and are therefore more elastic. Also, binding minimum wages, explicit ones or implicit ones in the form of unemployment insurance, may allow firms to hire additional labor at the going wage.

\subsubsection{Output and Inflation in Model $\Pi$ Equilibrium}

This section presents the output and inflation dynamics in Model $\Pi$ Equilibrium and compares these with the behavior of U.S. data. It is assumed throughout the section that the elasticity of labor supply is given by $\varepsilon_{n, w}=1.8$, which is at the lower end of values for which Model $\Pi$ Equilibria exist. ${ }^{39}$

Figure 7 depicts the auto- and crosscorrelations of output and inflation in Model $\Pi$ Equilibrium. The data is shown for 6 periods, which corresponds to 24 quarters of U.S. data if each model period is interpreted as 1 year, which seems reasonable given the degree of price stickiness. ${ }^{40}$ The shapes of the auto- and crosscorrelations match remarkably well the correlations in the data. Output and inflation are persistent. They are positively correlated for short lags and negatively for longer lags. Output is a positive leading indicator for inflation and inflation is a leading indicator of future output losses.

Figure 8 shows the impulse responses for a demand shock hitting the economy in period 1. The initially sluggish price response in period 2 causes output to remain above equilibrium

\footnotetext{
${ }^{39}$ The effects of larger elasticity levels are discussed at the end of the section.

${ }^{40}$ The figure depicts the correlations for the unfiltered data. Transforming this 'yearly' data into 4 equal quarterly values and applying the bandpass filter that has been used for detrending the data leads to a very similar graph. Unfiltered data are shown because they allow for a clear interpretation in terms of the model's mechanisms.
} 
in the period 2. In period 3 inflation increases even further and causes a demand slump in period 3. Output and inflation then slowly return to their equilibrium values. The impulse responses closely match the estimated impulse responses for the U.S. shown in figure 4 .

To understand how this result emerges consider agents' estimates of the two forecast models in Model $\Pi$ Equilibrium: ${ }^{41}$

$$
\begin{aligned}
& \text { Model Y : } \Pi_{t}=(1-0.467)+\frac{0.467}{y^{s s}} y_{t-1} \\
& \text { Model } \Pi: \Pi_{t}=(1-0.688)+0.688 \Pi_{t-1}
\end{aligned}
$$

The estimate of the AR-coefficient of Model $Y$ shows that inflation in a Model $\Pi$ Equilibrium is reacting much weaker to an output deviation than in Model Y Equilibrium where the same coefficient is given by $\frac{1}{y^{s s}}$, see equation (12).

This relatively weak reaction of inflation to a demand shock can be explained as follows. In general, inflation increases because firms expect either inflation or real wages to increase. When a demand shock hits the economy current prices are preset and, given that Model $\Pi$ forecasts condition on current inflation, inflation expectations are equally preset. Thus, cost expectations must initially drive inflation.

With future inflation expected to be unchanged, current excess demand is expected to persist into the next period, which will increase expected future real wages. Since labor supply is relatively elastic, costs are expected to increase only slightly and thereby cause a rather weak inflation reaction.

Yet, once inflation has picked up, inflation expectations will start to pick up and then start to drive actual inflation. This explains why inflation in the second period after the shock is higher than in the first period in the upper-right graph of figure 8.

Another noteworthy feature of Model $\Pi$ Equilibria is that it generates real wages that are lagging over the output cycle, a feature stressed by Galí and Gertler (1999). The panel

\footnotetext{
${ }^{41} y^{s s}$ can be left unspecified because it only determines the average output level.
} 
on the right of figure 9 displays the correlation coefficient between the real wage and output in Model $\Pi$ Equilibrium. Although output is positively correlated with current wages (due to an upward sloping labor supply function), output shows a higher correlation with the wage in the next model period. Since inflation and inflation expectations are lagging the cycle workers expect a higher inflation tax after the peak of the cycle. This shifts the labor supply curve upwards and results in higher real wages despite a decreasing output level.

The panel on the left of figure 9 displays the same correlation in a Model Y Equilibrium. Since output and inflation are white noise, output is only correlated with current wages but neither with leading nor lagging values.

I now briefly discuss the effects of higher elasticity values for the impulse responses in the top row of figure 8 . The initial inflation response will be more sluggish since costs are expected to increase even less with more elastic labor supply. Therefore, output will be higher and inflation lower in period 2. In period 3, when inflation expectations are picking up, there are two opposing effects. On the one hand inflation shows higher persistence with higher elasticities (see figure 5); therefore, given the inflation rate for period 2, expectations for period 3 inflation will be higher. On the other hand the inflation reaction in period 2 is more sluggish. As it turns out, the net effect is positive and inflation in period 3 is higher and output lower than shown in figure 8.

Higher elasticity values, thus, generate a more sluggish initial inflation reaction but a stronger reaction thereafter. This results in a shorter length of the cycle and causes the correlations in figure 7 to cross the axis at an earlier date.

\section{Discussion}

This section discusses two important issues concerning the plausibility of Model $\Pi$ Equilibria: 1.The degree of non-rationality and the utility loss associated with inefficient forecasting in a Model $\Pi$ Equilibrium, and 2.The generality of the result that forecasting restrictions might 
give rise to equilibria where optimal forecasts are only constrained rational.

\subsection{Forecast Inefficiency in Model П Equilibrium}

A diagnostic test for the rationality of forecasts in Model $\Pi$ Equilibrium can be based on the correlation structure of forecast errors. The panel on the left-hand side of figure 10 displays the autocorrelations for the one-step-ahead forecast error in Model $\Pi$ Equilibrium for a labor supply elasticity of $\varepsilon_{n, w}=1.8 .{ }^{42}$ Unsurprisingly, the figure shows that forecast errors are correlated indicating that forecasts are inefficient.

How long would it take to discover the inefficiency? The panel on the right-hand side of figure 10 presents the rejection probabilities of Box-Pierce tests of the null hypothesis that forecast errors are white noise in Model $\Pi$ Equilibrium. ${ }^{43}$ With 20 to 30 data points rejection frequencies are rather low, while with 50 data points rejection is almost certain.

Table 1 reports the expected number of observations for which the tests deliver the first rejection. ${ }^{44}$ Depending on the precise test used one can expect the class of forecast models to be in place for around 33 observations, i.e. more than three decades with yearly data or more than 8 years in the case of quarterly data. This seems to be a sufficiently long time period for a Model $\Pi$ Equilibrium to be economically relevant.

Table 1: Specification Tests

\begin{tabular}{|l|l|l|l|}
\hline Box-Pierce Test & Lag 1 & Lag 1-2 & Lag 1-3 \\
\hline Expected duration until rejection & 33.8 & 39.2 & 27.3 \\
\hline
\end{tabular}

\footnotetext{
${ }^{42}$ This is the value used in the previous section. Higher elasticities lead to very similar error structures. The auto-correlations have been obtained numerically from 10000 simulated data points.

${ }^{43}$ The shown rejection probabilities are for the asymptotic $1 \%$ critical value of the test and have been obtained by Monte Carlo simulations of 10000 series.

${ }^{44}$ Agents are assumed to perform a Box-Pierce test with a $1 \%$ critical value each time a new data point is obtained. The table reports the expected number of observations at which the first rejection is obtained based on 10000 Monte Carlo simulations.
} 
Although the correlation structure of forecast errors is informative about whether forecasts are rational, it remains uninformative about the utility costs associated with inefficient forecasting. At the same time utility costs seem to be an economically more relevant criterion for evaluating the degree non-rationality than the statistical correlation properties of forecast errors.

The first line of equation (14) reveals that the best possible forecast model in Model $\Pi$ Equilibrium predicts with zero error. ${ }^{45}$ The size of Model $\Pi$ 's forecast error is thus a quadratic approximation to the utility loss associated with the use of simple regression models. Interestingly, the size of Model $\Pi$ 's forecast errors depends on the variance of the demand shocks. When the variance of demand shocks approaches zero, the forecast errors of Model $\Pi$ disappear: Since Model $\Pi$ forecasts are unbiased, forecasts will become rational in the limit when shocks are absent. This is a consequence of the more general observation that perfect foresight equilibria can be the limit of constrained rational equilibria of stochastic economies with vanishing noise, see Adam (2002a).

The previous observation implies that the utility loss that agents incur by using Model $\Pi$ decreases with the variance of the demand shock and can be made arbitrarily small. Moreover, due to an argument made by Akerlof and Yellen (1985) the agent's utility loss is of an order smaller than the size of the forecast errors. Further results from Cochrane (1989) indicate that utility losses associated with non-optimal consumption behavior are in the order of a few cents per month given the variability of U.S. data.

All this suggests that the utility loss associated with use of Model $\Pi$ is relatively small despite the statistical properties of forecast errors.

\subsection{Generality of Results}

As argued in the introduction, the essential ingredient allowing for equilibria with inefficient equilibrium expectations is that the class of forecast models has an openness property where

\footnotetext{
${ }^{45}$ This is the case because supply shocks are absent.
} 
the use of some forecast model causes the actual law of motion of the forecasted variable to lie outside the class.

To assess the generality of this mechanism one would need to answer the following questions: How likely is it that a given class of forecast models is open? Which conditions insure that the class is closed, i.e. that the induced actual laws always remain inside the considered class?

For the present model the answer to the second questions seems obvious at first. Adding to the two forecast models considered thus far a model containing both lagged output and lagged inflation will lead to a class of forecast models that is closed: the induced laws of motion will then depend at most on lagged output and inflation, see equation (6).

The previous point, however, is not entirely convincing. Once agents use forecast equations with two variables they might as well consider other two variable systems, including an equation where inflation is assumed to depend on lagged and twice lagged inflation. Use of the latter forecast model will lead to an actual law of motion where inflation depends on three variables (two lags of inflation and one lag of output, see equation (6)) and the class of forecast models will be open again. A similar logic applies when allowing for three or more variables in the forecast equations.

In general openness in linear models remains always a possibility when the maximum number of lags is finite. ${ }^{46}$ Only when the number of lags is arbitrary, the class of forecast models is guaranteed to be closed: linear forecasts in a linear model will lead to linear actual laws of motion, which are contained in the class by definition.

Closedness is likely to be even more difficult to obtain when allowing for non-linear forecasts and/or non-linear models. Moreover, models deviating from the representative agent assumption and allowing agents to have heterogeneous forecasting capabilities may

\footnotetext{
${ }^{46}$ However, openness is only a necessary condition for inefficient expectations equilibria to exists. Once the class of models increases, the class of competing models increases and the candiate model projecting the actual law of motion outside the considered class is less likely to be the best approximation to that actual law.
} 
also increase the likelihood of openness in the sense above.

In the light of the previous discussion the openness property of the class of simple regression models considered in this paper is a good feature since openness is likely to be obtained in many situations involving forecasting constraints.

\section{Outlook on Work Ahead}

Some questions related to the findings in this paper deserve further attention.

Firstly, it is desirable to evaluate the imposed forecasting restrictions in an independent way. Such evaluation allows to assess whether or not by choosing an appropriate forecasting restriction the present model has been overfitted to the data. In Adam (2002b) I have implemented the model in the experimental laboratory. Model $\Pi$ Equilibria and simple regression models have been extremely effective in explaining the experimental data, which should increase confidence into the results derived in this paper. Further investigations using real data, e.g. expectations survey data, may shed additional light on the plausibility of Model ПI Equilibria.

Secondly, output and consumption in Model $\Pi$ Equilibrium display a higher variance than in Model Y Equilibrium. This suggests that Model $\Pi$ Equilibria are Pareto dominated by Model Y Equilibria for low enough discount rates. ${ }^{47}$ This raises the question whether suitable policies could improve upon the situation and prevent the economy from converging to a Model ПI Equilibrium.

Finally, the construction of models where agents differ in their forecasting constraints would be of interest. Does heterogeneity of forecasts generated along these lines makes it even more difficult for forecasters to detect the true underlying economic relationships?

\footnotetext{
${ }^{47}$ However, entrepreneurs and workers profit differently from output fluctuations.
} 


\section{Appendix}

\subsection{Vector Autoregression}

A VAR with two lags and a constant was estimated by OLS regression. The data consists of bandpass-filtered quarterly inflation and output data depicted in figure 2. The estimation results are :

\begin{tabular}{|l|l|l|l|l|}
\hline & $\Pi_{t}$ & Std.Error & $y_{t}$ & Std.Error \\
\hline const. & 0.020562 & 0.089495 & 0.00033680 & 0.0016824 \\
\hline$\Pi_{t-1}$ & 0.056692 & 0.16023 & -0.0087039 & 0.0030122 \\
\hline$\Pi_{t-2}$ & -0.39029 & 0.15483 & -0.0042423 & 0.0029107 \\
\hline$y_{t-1}$ & 22.005 & 8.7542 & 0.29932 & 0.16457 \\
\hline$y_{t-2}$ & 15.306 & 9.2518 & -0.035335 & 0.17393 \\
\hline$\sigma$ & 0.55062 & - & 0.010351 & - \\
\hline$R^{2}$ & 0.75406 & - & 0.69924 & - \\
\hline
\end{tabular}

The actual and the fitted values are shown in figure 11. Figure 12 depicts the autocorrelation of the regression errors. If one required regressors to be significant at the $1 \%$ level, one could test down to a model with just 1 lag. Figure 13 shows the impulse response functions for this case and illustrates the robustness of the impulse responses.

\subsection{Calculation of the Rational Expectations Equilibria}

Consider a stochastic linear expectational difference equation of the form

$$
x_{t}=k+B_{0} E_{t-1}\left[x_{t}\right]+B_{1} E_{t-1}\left[x_{t+1}\right]+D x_{t-1}+u_{t}
$$

with $x_{t}, u_{t}, k \in R^{n}, B_{0}, B_{1}, D \in R^{n \times n}$, and $B_{1} \neq 0, D \neq 0$. The minimum state variable solutions of (15) take the form

$$
x_{t}=a+B x_{t-1}+u_{t}
$$


provided there exists a real solution to the matrix quadratic equation

$$
B_{1} B^{2}-\left(B_{0}-I\right) B+D=0
$$

see chapter 10 in Evans and Honkapohja (2001). Then $a$ is given by

$$
\left(I-B_{0}-B_{1}(1+B)\right) a-k=0
$$

The AR-solutions can be calculated by solving the matrix equations (16) and (17) for $a$ and $B$. Some lengthy algebra shows that there are two rational expectations solutions, namely the ones given by (8) and (9).

\subsection{Stability of Rational Expectations under Least Squares Learn- ing}

The stability of the rational expectations equilibria (8) and (9) under least-squares learning is governed by the so-called E-stability criterion, see Evans and Honkapohja (1998). Using

$$
\begin{aligned}
E_{t-1}\left[\Pi_{t}\right] & =\alpha+\beta y_{t-1} \\
E_{t-1}\left[\Pi_{t+1}\right] & =\alpha+\beta E_{t-1}\left[y_{t}\right] \\
& =\alpha+\beta\left(y^{s}+\frac{1}{\Pi^{s}} y_{t-1}-\frac{y}{\left(\Pi^{s}\right)^{2}}\left(\alpha+\beta y_{t-1}\right)\right)
\end{aligned}
$$

to substitute the expectations in (6) and using $\Pi^{s}=1$, one obtains

$$
\Pi_{t}=T_{a}(\alpha, \beta)+T_{b}(\beta) y_{t-1}
$$

where

$$
\begin{aligned}
T_{a}(\alpha, \beta) & =-1+\left(2-\frac{1}{\varepsilon_{n, w}}\right) \alpha+\beta y(1-\alpha) \\
T_{b}(\beta) & =\frac{1}{y \varepsilon_{n, w}}+\left(1-\frac{1}{\varepsilon_{n, w}}\right) \beta-y \beta^{2}
\end{aligned}
$$


The associated differential equation is given by

$$
\left(\begin{array}{c}
\frac{\partial \alpha}{\partial t} \\
\frac{\partial \beta}{\partial t}
\end{array}\right)=\left(\begin{array}{c}
T_{a}(\alpha, \beta) \\
T_{b}(\alpha, \beta)
\end{array}\right)-\left(\begin{array}{c}
\alpha \\
\beta
\end{array}\right)
$$

and E-Stability (E-Instability) is satisfied when the eigenvalues of

$$
\left(\begin{array}{ll}
\frac{\partial T_{a}(\alpha, \beta)}{\partial \alpha} & \frac{\partial T_{a}(\alpha, \beta)}{\partial \beta} \\
\frac{\partial T_{b}(\alpha, \beta)}{\partial \alpha} & \frac{\partial T_{b}(\alpha, \beta)}{\partial \beta}
\end{array}\right)
$$

are smaller (larger) than one.

For the stationary rational expectations solution (8) the eigenvalues of (18) are given by $\lambda_{1}=1-\frac{1}{\varepsilon_{n, w}}$ and $\lambda_{2}=-\frac{1}{\varepsilon_{n, w}}$ and for the non-stationary solution (9) by $\lambda_{1}=2$ and $\lambda_{2}=2+\frac{1}{\varepsilon_{n, w}}$. This proves that the stationary rational expectations solution is stable and that the non-stationary rational expectations solution unstable under least squares learning of Model Y.

\subsection{Calculating $\beta_{\Pi}^{*}$}

Without loss of generality ignore the constant in (14) and write it as

$$
z_{t}=B z_{t-1}+u_{t}
$$

with $\operatorname{Var}\left(u_{t}\right)=\Omega, \operatorname{Var}\left(z_{t}\right)=\Sigma, \operatorname{Cov}\left(z_{t}, z_{t-1}\right)=\Gamma$, and $B=\left(b_{i, j}\right)$. Taking variances on both sides of (19) yields

$$
\Sigma=B \Sigma B^{\prime}+\Omega
$$

which implies

$$
\begin{aligned}
\operatorname{vec}(\Sigma) & =(B \otimes B) \operatorname{vec}(\Sigma)+\operatorname{vec}(\Omega) \\
& =(I-B \otimes B)^{-1} \operatorname{vec}(\Omega)
\end{aligned}
$$


Multiplying (19) by $z_{t-1}$ and taking expectations one obtains the covariance with lagged variables:

$$
\Gamma=B \Sigma
$$

Using equations (20) and (21) and remembering that

$$
\Omega=\left(\begin{array}{cc}
0 & 0 \\
0 & \sigma_{v}^{2}
\end{array}\right)
$$

the matrices $\Sigma$ and $\Gamma$ are easily calculated. Using the expression for the variance of $\Pi_{t}$ from $\Sigma$ and the expression for the covariance of $\Pi_{t}$ and $\Pi_{t-1}$ from $\Gamma$ one obtains

$$
\begin{aligned}
\beta_{\Pi} & =\frac{\operatorname{cov}\left(\Pi_{t}, \Pi_{t-1}\right)}{\operatorname{var}\left(\Pi_{t}\right)} \\
& =\frac{b_{11}+b_{22}}{1+\left(b_{11} b_{22}-b_{12} b_{21}\right)} \\
& =\frac{\left(1+\beta_{\Pi}-\frac{1}{\varepsilon_{n, w}}\right) \beta_{\Pi}+1-\frac{1}{\varepsilon_{n, w}}}{\left(1+\beta_{\Pi}-\frac{1}{\varepsilon_{n, w}}\right) \beta_{\Pi}+1}
\end{aligned}
$$

The unique real solution to this equation is given by

$$
\begin{aligned}
\beta_{\Pi}^{*} & =\sqrt[3]{z}-\frac{1}{9} \frac{3 \varepsilon_{n, w}-1}{\left(\varepsilon_{n, w}\right)^{2} \sqrt[3]{z}}+\frac{1}{3 \varepsilon_{n, w}} \\
\text { where } & \\
z & =\frac{1}{54} \frac{2-9 \varepsilon_{n, w}-27\left(\varepsilon_{n, w}\right)^{2}+27\left(\varepsilon_{n, w}\right)^{3}}{\left(\varepsilon_{n, w}\right)^{3}} \\
& +\frac{1}{18} \frac{\sqrt{3}}{\left(\varepsilon_{n, w}\right)^{2}} \sqrt{\left(-5+26 \varepsilon_{n, w}+9\left(\varepsilon_{n, w}\right)^{2}-54\left(\varepsilon_{n, w}\right)^{3}+27\left(\varepsilon_{n, w}\right)^{4}\right)}
\end{aligned}
$$

\subsection{Stability of Model П Equilibrium under Least Squares Learn- ing}

E-Stability governs the stability under least squares learning, see Evans and Honkapohja (1998). The differential equation determining the stability of Model $\Pi$ Equilibria is given 
by

$$
\frac{\partial \beta}{\partial \tau}=T(\beta)-\beta
$$

where $T(\beta)$ is given by equation (22). Whenever (24) is locally asymptotically stable at the

Model $\Pi$ equilibrium, i.e. when $\frac{\partial T(\beta)}{\partial \beta}<1$ at the equilibrium value of $\beta$, then the Model

$\Pi$ equilibrium is stable under least squares learning. Figure 14 shows $\frac{\partial T(\beta)}{\partial \beta}$ for the relevant parameter space of $\varepsilon_{n, w}$ and reveals that $\beta$ converges to its equilibrium value under least squares learning. From $\alpha=1-\beta$ it follows that Model $\Pi$ equilibria are stable under least squares learning.

\section{References}

Adam, Klaus, "Learning and Equilibrium Selection in a Monetary Overlapping Generations Model with Sticky Prices," Review of Economic Studies (forthcoming), 2002.

_ _ "Should Macroeconomists Consider Restricted Perceptions Equilibria? Evidence from the Experimental Laboratory," University of Frankfurt Mimeo, 2002.

Akerlof, George A. and Janet L. Yellen, "A Near-Rational Model of the Business Cycle with Wage and Price Inertia," Quarterly Journal of Economics, 1985, 100, 823-838.

Anderson, Robert M. and Hugo Sonnenschein, "Rational Expectations Equilibrium with Econometric Models," Review of Economic Studies, 1985, 52, 359-369.

Arifovic, Jasmina and James Bullard, "Learning in Macroeconomic Models," Macroeconomic Dynamics, 2001, 5, 143-147.

Ball, Laurence, "Near-Rationality and Inflation in Two Monetary Regimes," Johns Hopkins University Mimeo, 2000.

Bossaerts, Peter, The Paradox of Asset Pricing, Princeton: Princeton University Press, 2002. 
Brock, William A. and Cars H. Hommes, "A Rational Route to Randomness," Econometrica, 1997, 65, 1059-1095.

Cagan, P., The Monetary Dynamics of Hyper-Inflation, in Milton Friedman (ed.), "Studies in the Quantity Theory of Money", University of Chicago Press, 1956.

Chari, V.V., P.J. Kehoe, and E.R. McGrattan, "Sticky Price Models of the Business Cycle: Can the Contract Multiplier Solve the Persistence Problem?," Econometrica, $2000,68,1151-1179$.

Christiano, Lawrence J., Martin Eichenbaum, and Charles Evans, "Monetary Policy Shocks: What Have We Learned and to What End?," in John B. Taylor and Michael Woodford, eds., Handbook of Macroeconomics, Amsterdam: Elsevier, 1999, pp. 65-148.

Christiano, M. Eichenbaum L. and C. Evans, "Sticky Price and Limited Participation Models of Money: A Comparison," European Economic Review, 1997, 41, 1201-49.

Cochrane, John H., "The Sensitivity of Tests of the Intertemporal Allocation of Consumption to Near-Rational Alternatives," American Economic Review, 1989, 79, 319-337.

Croushore, Dean, "Inflation Forecasts: How Good are They?," Federal Reserve Bank of Philadelphia Business Review, 1996, May/June.

__ , "Evaluating Inflation Forecasts," Federal Reserve Bank of Philadephia Working Paper No.98-14, 1998.

Dixit, Avinash K. and Joseph E. Stiglitz, "Monopolistic Competition and Optimum Product Diversity," American Economic Review, 1977, 67, 297-308.

Evans, George and Garey Ramey, "Expectation Calculation and Macoeconomic Dynamics," American Economic Review, 1992, 82, 207-224.

Evans, George W. and Seppo Honkapohja, "Adaptive Forecasts, Hysteresis, and Endogenous Fluctuations," Economic Review of the Federal Reserve Bank of San Fransico, 1993, 1, 3-13. 
_ _ and _ _ "Economic Dynamics with Learning: New Stability Results," Review of Economic Studies, 1998, 65, 23-44.

and __ Learning and Expectations in Macroeconomics, Princeton: Princeton University Press, 2001.

Friedman, Benjamin M., "Survey Evidence on the 'Rationality' of Interest Rate Expectations," Journal of Monetary Economics, 1980, 6, 453-465.

Fudenberg, Drew and David Levine, "Sef-Confirming Equilibrium," Econometrica, $1993,61,523-545$.

Fuhrer, Jeff and George Moore, "Inflation Persistence," Quarterly Journal of Economics, 1995, 110, 127-159.

Galí, Jordi and Mark Gertler, "Inflation Dynamics: A Structural Econometric Analysis," Journal of Monetary Economics, 1999, 44, 195-222.

Galí, Mark Gertler Jordi and David Lopez-Salido, "European Inflation Dynamics," European Economic Review, 2001, 45, 1237-1270.

Griffiths, R. Hill G. Judge W. and Tsoung-Chao Lee, The Theory and Practice of Econometrics, New York: John Wiley and Sons, 1980.

Hommes, C.H. and G. Sorger, "Consistent Expectations Equilibria," Macroeconomic Dynamics, 1997, 2, 287-321.

Kasa, Kenneth, "Learning, Large Deviations, and Recurrent Currency Crisis," International Economic Review (forthcoming), 2002.

Marcet, Albert and Juan Pablo Nicolini, "Recurrent Hyperinflations and Learning," American Economic Review (forthcoming), 1996.

Nelson, Edward, "Sluggish Inflation and Optimization Models of the Business Cycle," Journal of Monetary Economics, 1998, 伿, 303-322. 
Roberts, John M., "Is Inflation Sticky?," Journal of Monetary Economics, 1997, 39, 173196.

Sargent, Thomas J., The Conquest of American Inflation, Princeton: Princeton Univ. Press, 1999.

Stock, James and Mark Watson, "Business Cycle Fluctuations in US Macroeconomic Time Series," in John B. Taylor and Michael Woodford, eds., Handbook of Macroeconomics, Amsterdam: Elsevier, 1999, pp. 3-64.

Taylor, John B., "Staggered Price and Wage Setting in Macroeconomics," in John B. Taylor and Michael Woodford, eds., Handbook of Macroeconomics, Amsterdam: Elsevier, 1999, pp. 1009-1050.

Timmermann, Allan, "How Learning in Financial Markets Generates Excess Volatility and Predictability in Stock Prices," Quarterly Journal of Economics, 1993, 108, 11351145 . 


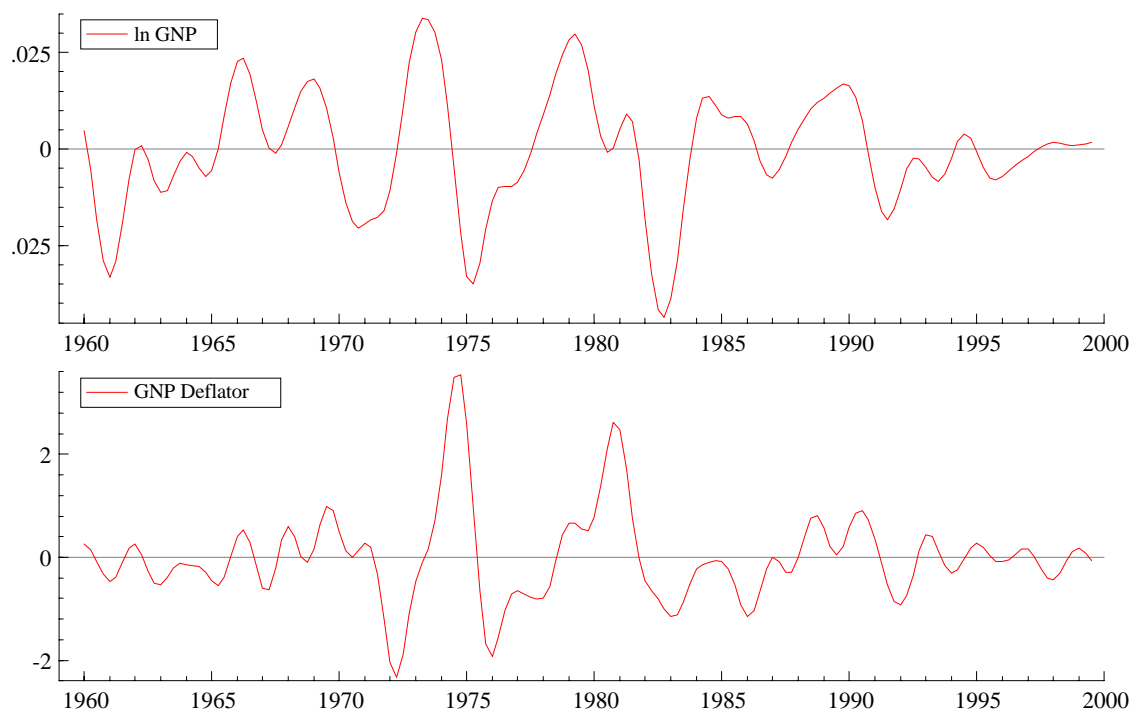

Figure 2: Detrended U.S. Data 


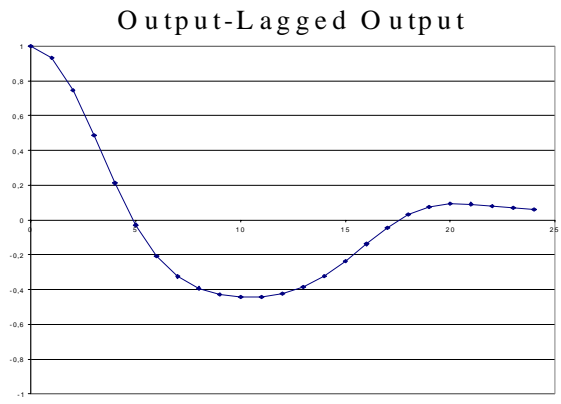

Inflation-Lagged O utput

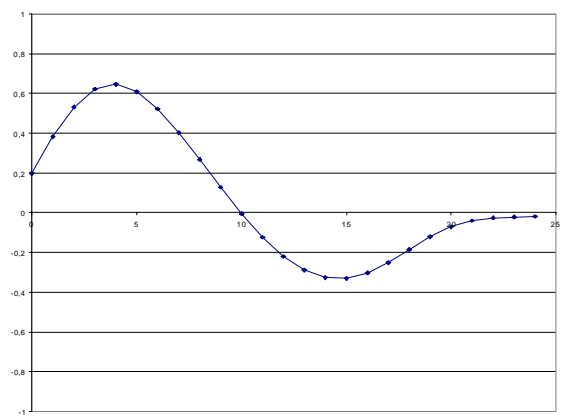

O utput-Lagged Inflation

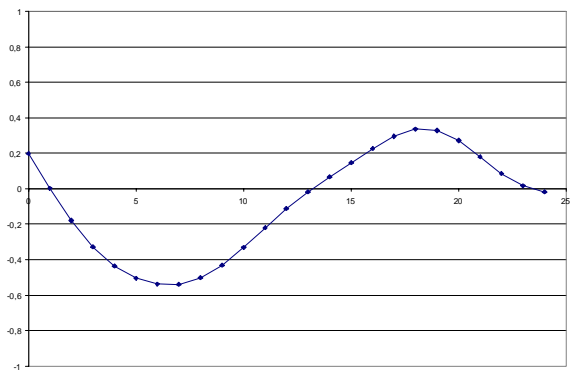

Inflation-Lagged Inflation

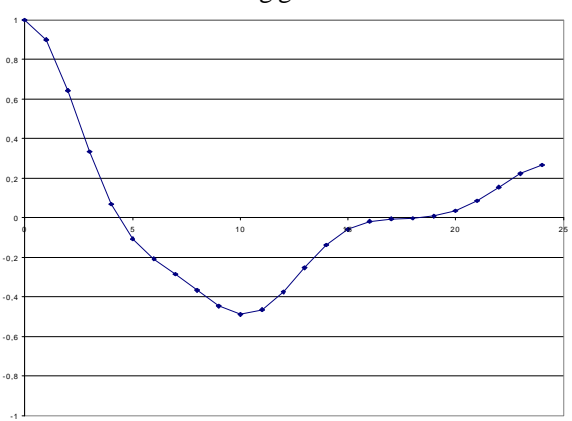

Figure 3: Auto- and crosscorrelations

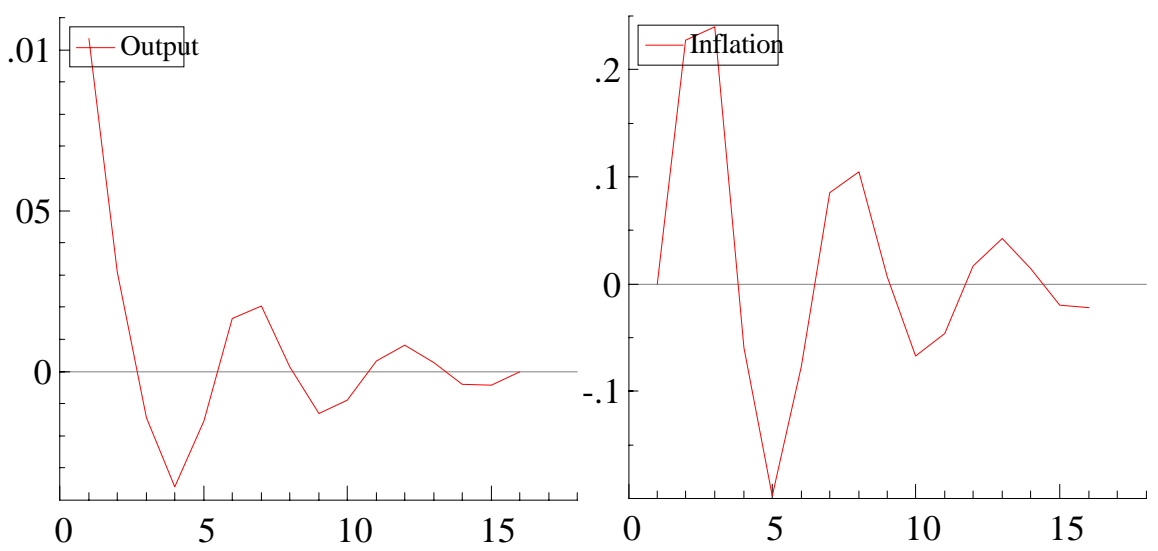

Figure 4: Impulse Responses to a Demand Shock, VAR(2) 


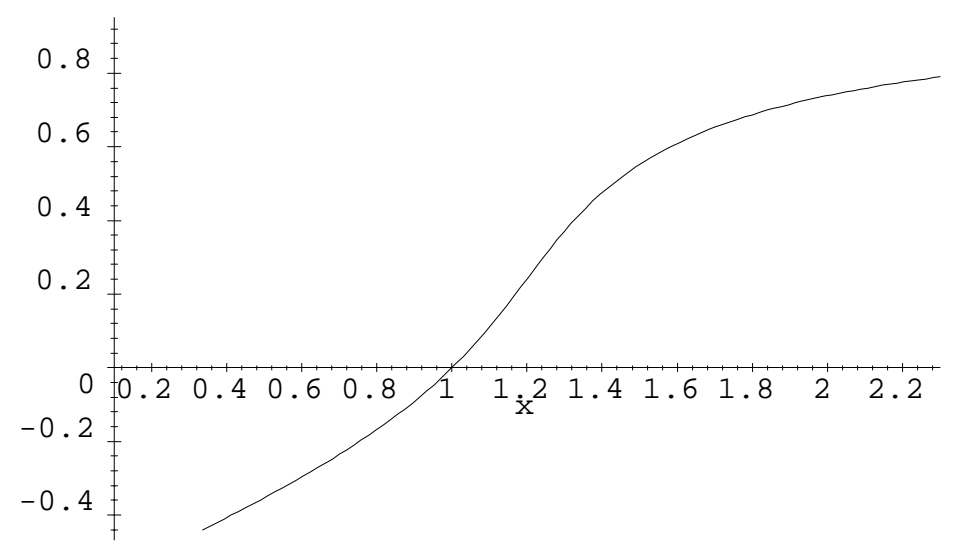

Figure 5: $\beta_{\Pi}^{*}$ as a function of $\varepsilon_{n, w}$

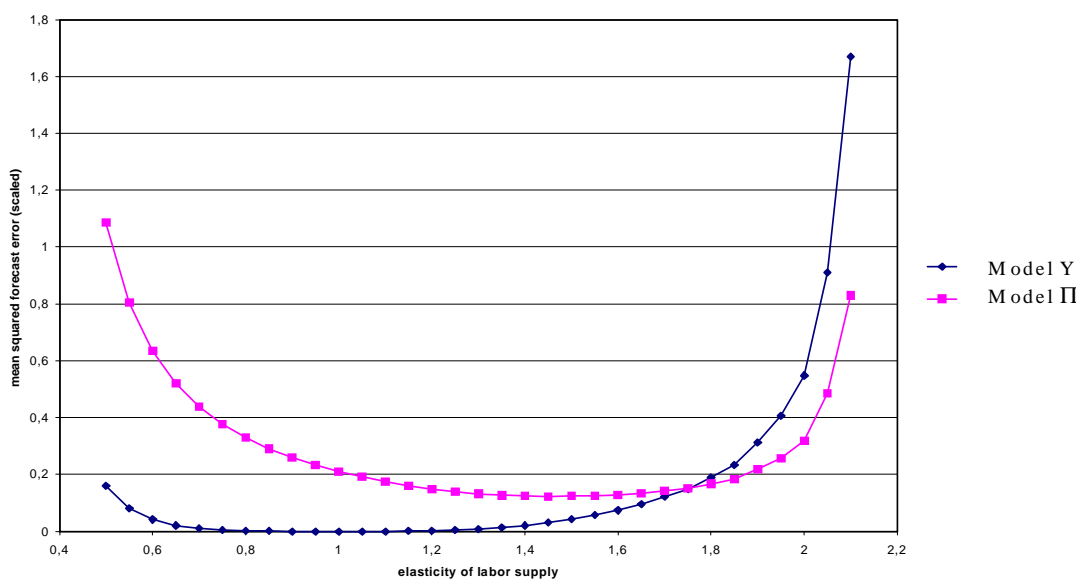

Figure 6: Mean Squared Forecast Errors 

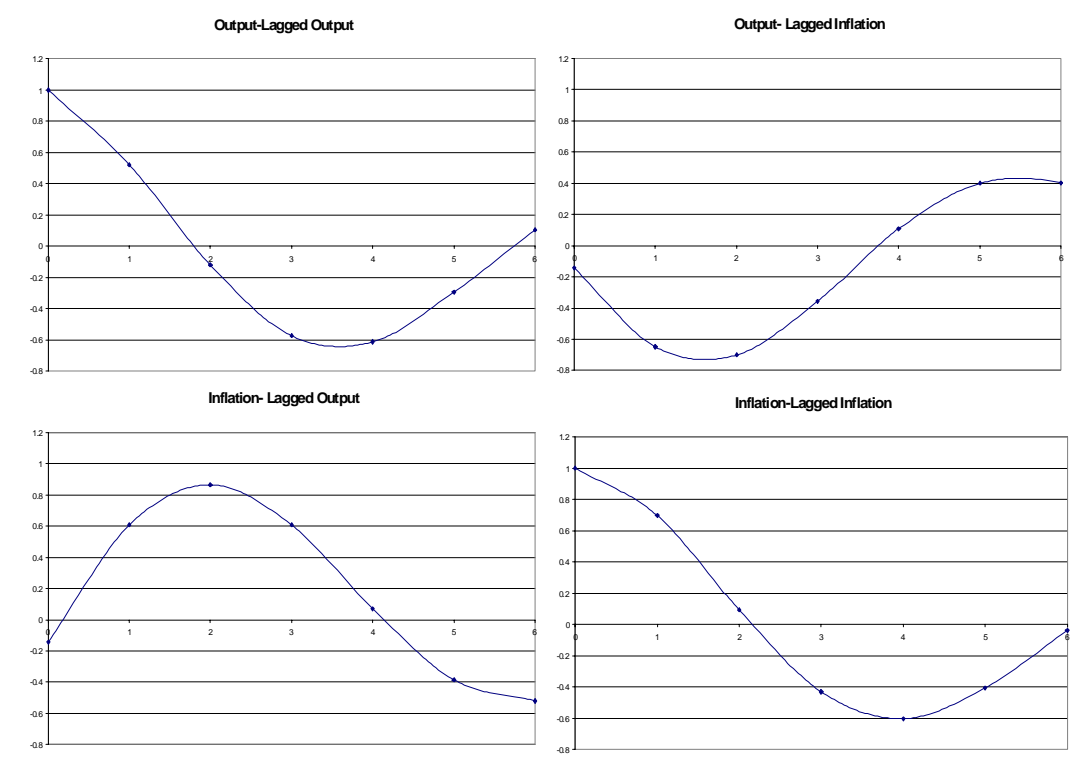

Figure 7: Auto- and crosscorrelations in Model $\Pi$ Equilibrium

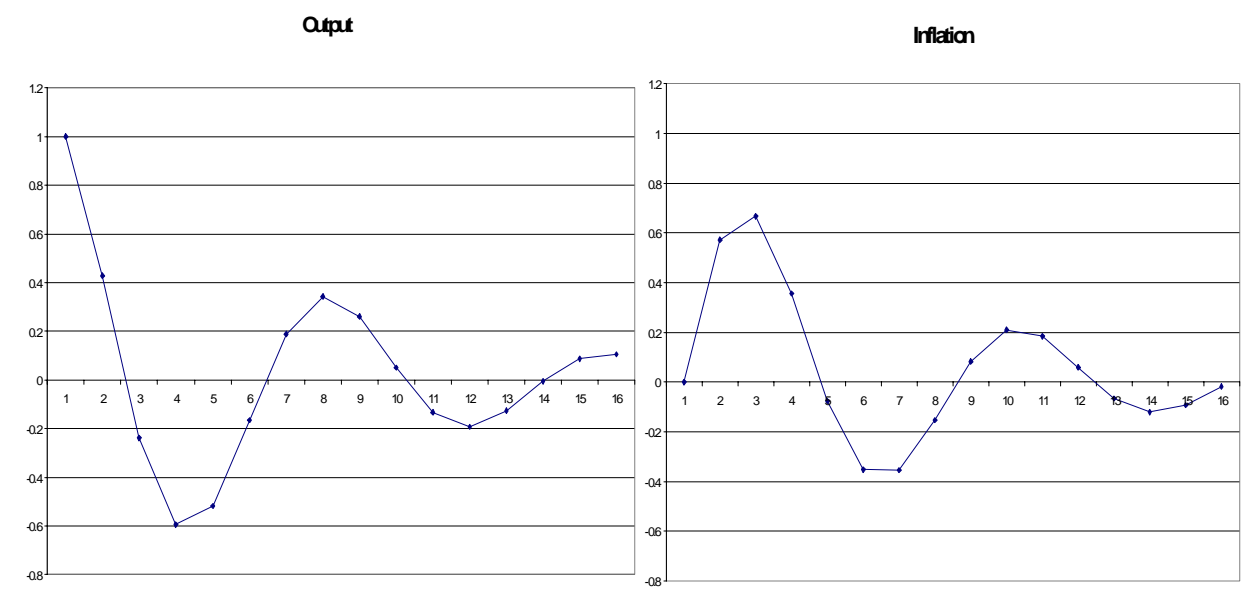

Figure 8: Impulse Responses to a Demand Shock in Model $\Pi$ Equilibrium 

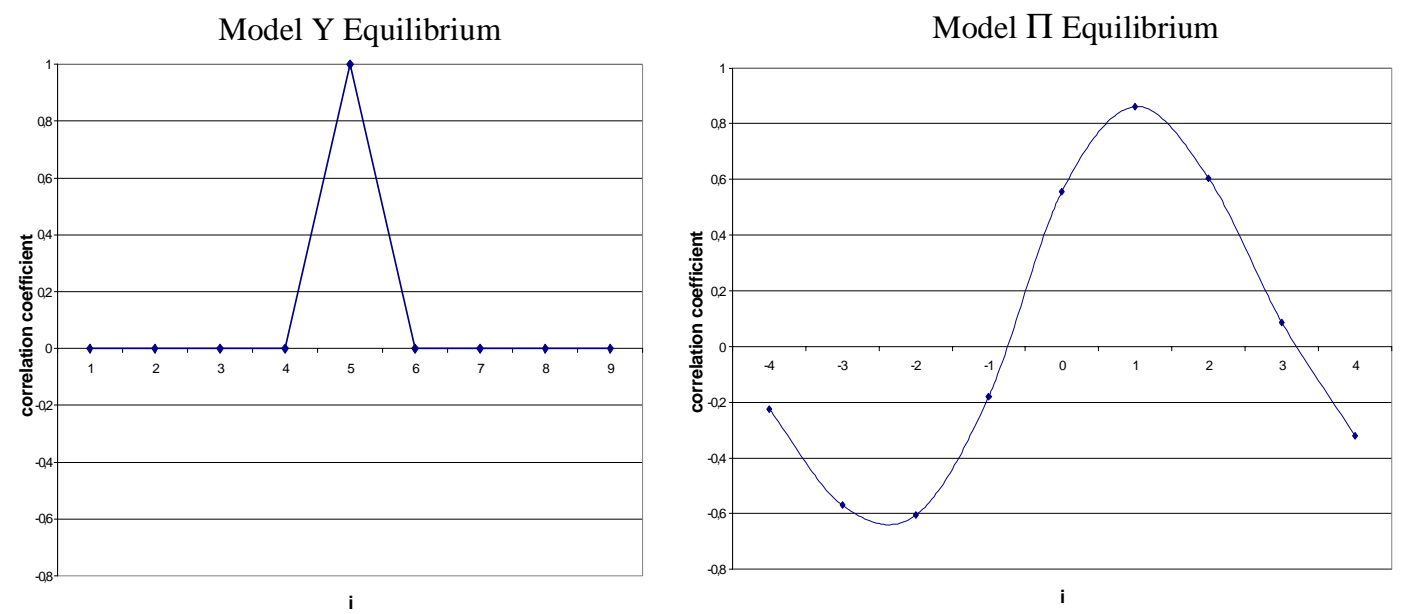

Figure 9: Correlation between ouput $(t)$ and wage $(t+i)$
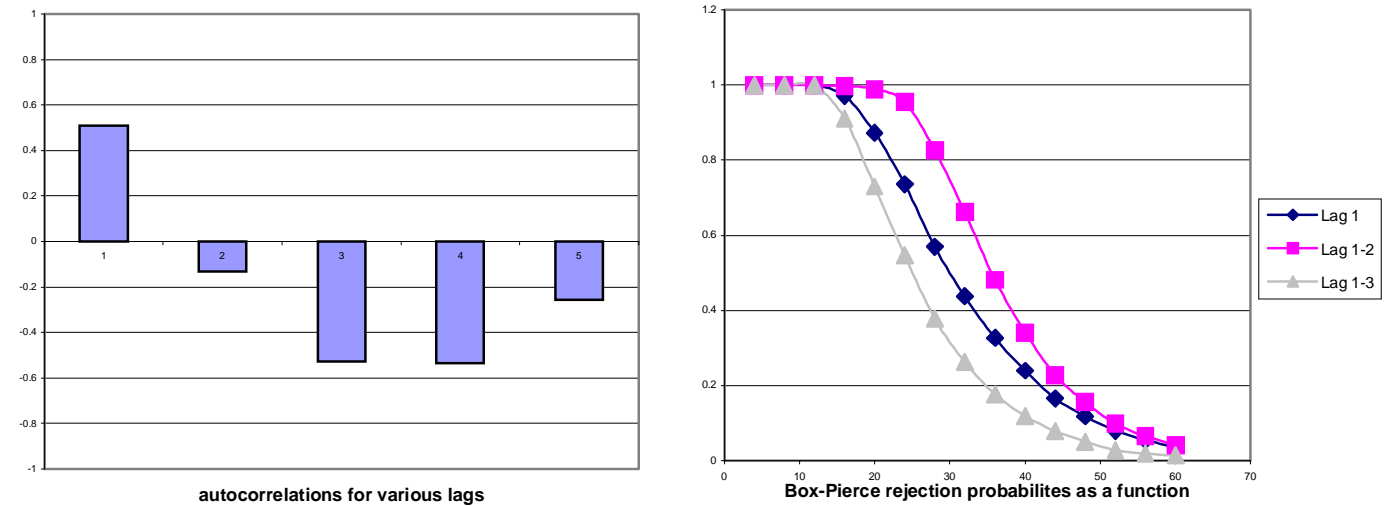

Figure 10: Forecast Errors 


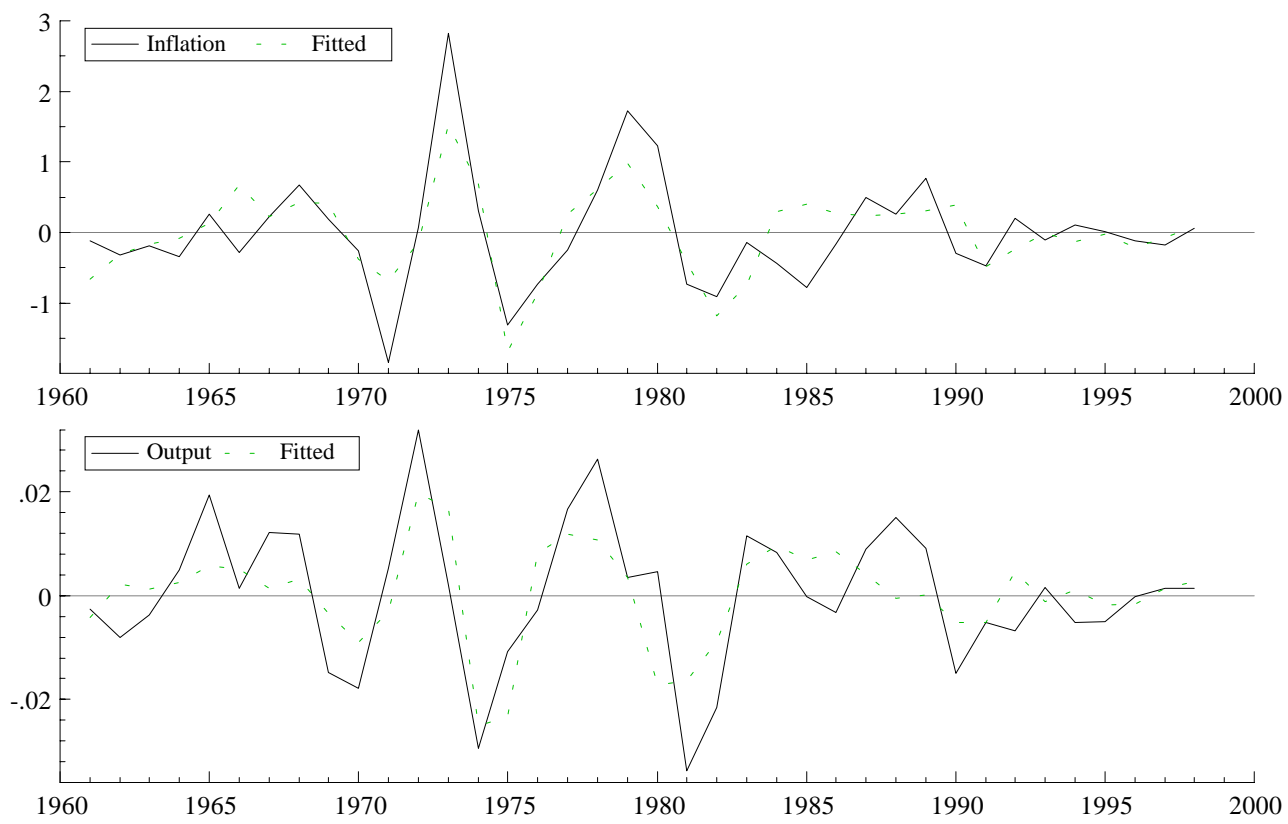

Figure 11: VAR: Actual and fitted values

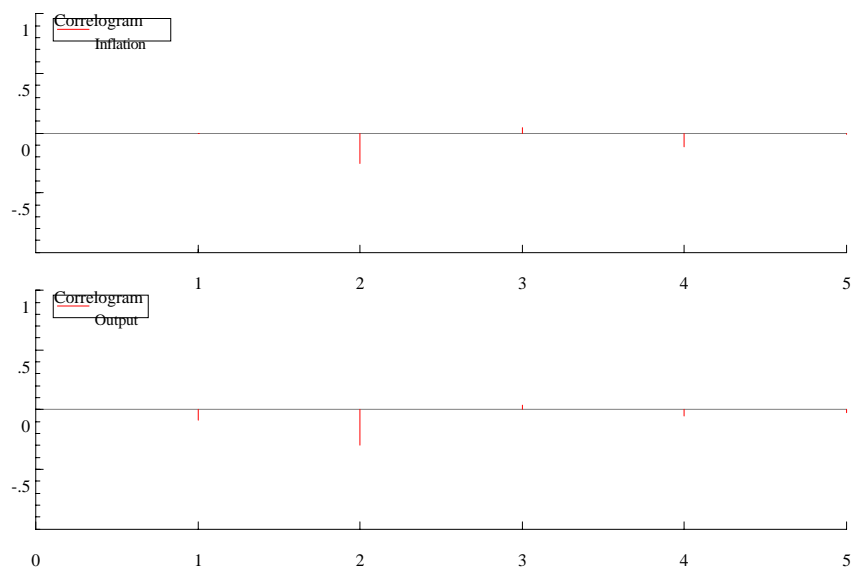

Figure 12: VAR: Autocorrelation of residuals 

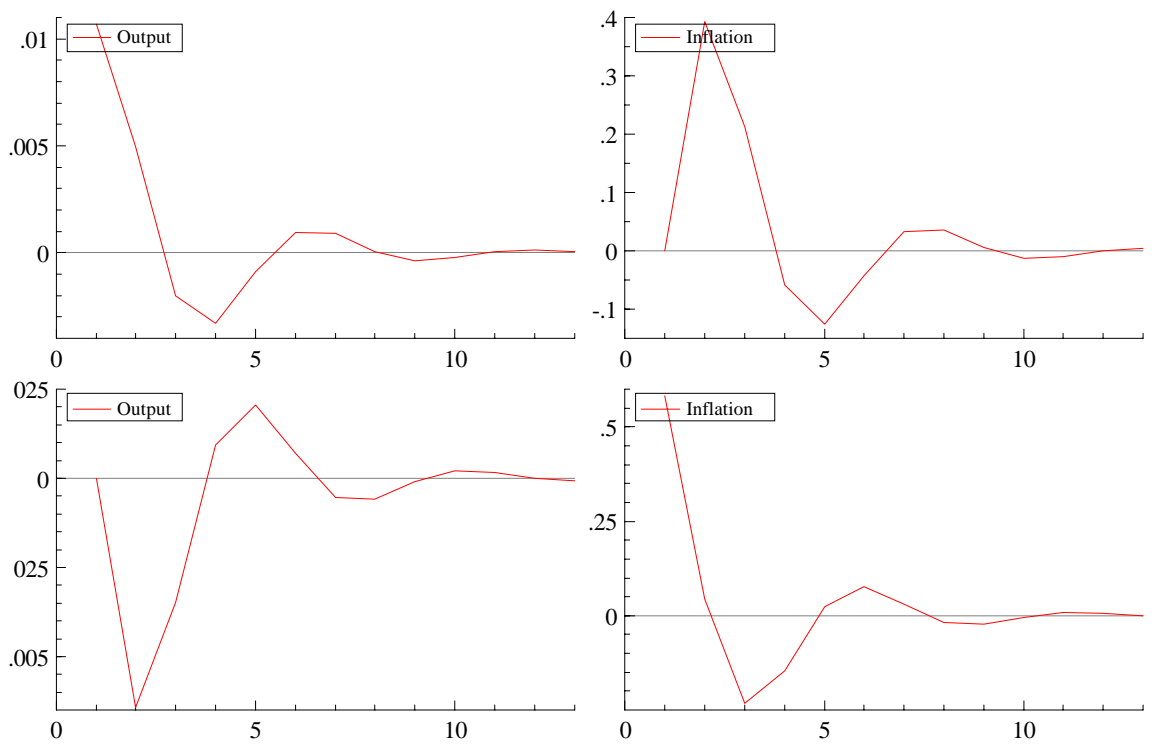

Figure 13: Impulse responses for VAR(1)

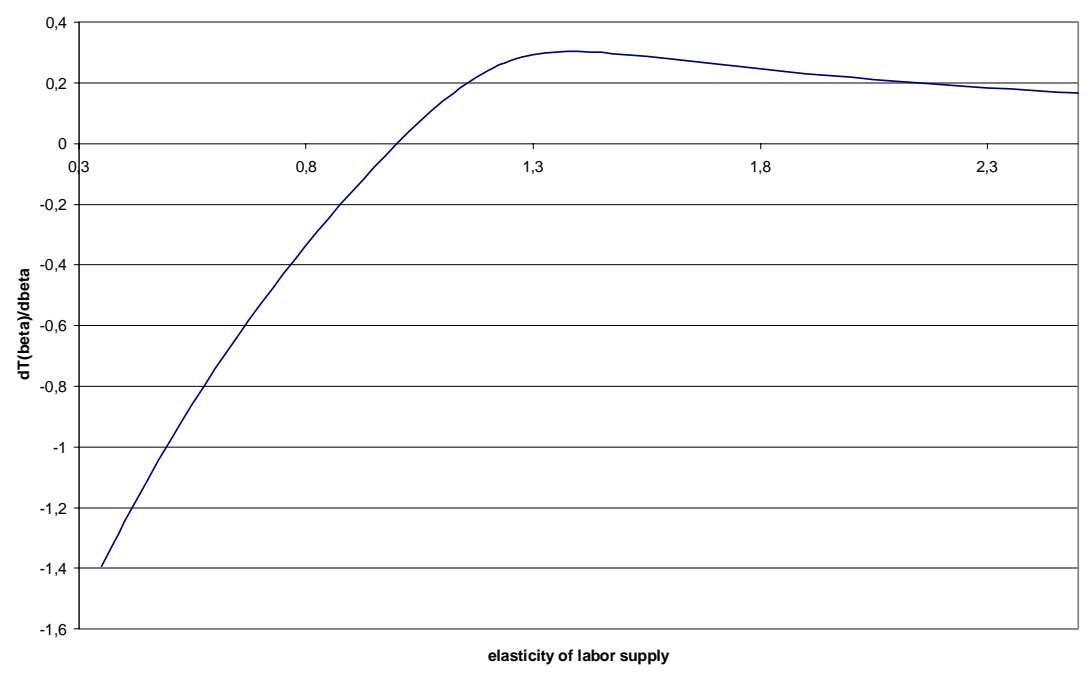

Figure 14: $\partial T(\beta) / \partial(\beta)$ as a function of $\varepsilon_{n, w}$ 


\section{CFS Working Paper Series:}

\begin{tabular}{|c|c|c|}
\hline No. & Author(s) & Title \\
\hline 2002/07 & $\begin{array}{l}\text { Werner Neus } \\
\text { Uwe Walz }\end{array}$ & $\begin{array}{l}\text { Exit Timing of Venture Capitalists in the Course } \\
\text { of an Initial Public Offering }\end{array}$ \\
\hline 2002/08 & $\begin{array}{l}\text { Andreas Bascha } \\
\text { Uwe Walz }\end{array}$ & $\begin{array}{l}\text { Financing Practices in the German Venture } \\
\text { Capital Industry } \\
\text { An Empirical Assessment }\end{array}$ \\
\hline 2002/09 & Marco Hoeberichts & The Credibility of Central Bank Announcements \\
\hline $2002 / 10$ & $\begin{array}{l}\text { Markus Haas } \\
\text { Stefan Mittnik } \\
\text { Marc S. Paolella }\end{array}$ & Mixed Normal Conditional Heteroskedasticity \\
\hline $2002 / 11$ & Elke Hahn & $\begin{array}{l}\text { Core Inflation in the Euro Area: } \\
\text { An Application of the } \\
\text { Generalized Dynamic Factor Model }\end{array}$ \\
\hline $2002 / 12$ & $\begin{array}{l}\text { Yunus Aksoy } \\
\text { Hanno Lustig }\end{array}$ & $\begin{array}{l}\text { On the Short and Long Term Real Effects of } \\
\text { Nominal Exchange Rates }\end{array}$ \\
\hline $2002 / 13$ & Andreas A. Jobst & $\begin{array}{l}\text { Collateralised Loan Obligations (CLOs) - } \\
\text { A Primer }\end{array}$ \\
\hline $2002 / 14$ & Andreas A. Jobst & $\begin{array}{l}\text { The Pricing Puzzle: The Default Term Structure } \\
\text { of Collateralised Loan Obligations }\end{array}$ \\
\hline $2002 / 15$ & Athanasios Orphanides & $\begin{array}{l}\text { Activist Stabilization Policy and Inflation: } \\
\text { The Taylor Rule in the 1970s }\end{array}$ \\
\hline 2003/01 & Klaus Adam & $\begin{array}{l}\text { Learning to Forecast and Cyclical Behavior of } \\
\text { Output and Inflation }\end{array}$ \\
\hline 2003/02 & Klaus Adam & $\begin{array}{l}\text { On the Relation between Robust and Bayesian } \\
\text { Decision Making }\end{array}$ \\
\hline
\end{tabular}

Copies of working papers are available at the Center for Financial Studies or can be downloaded (http://www.ifk-cfs.de). 